\title{
Climate change overtakes coastal engineering as the dominant driver of hydrological change in a large shallow lagoon
}

\author{
Peisheng Huang ${ }^{1,2}$, Karl Hennig ${ }^{3}$, Jatin Kala ${ }^{4}$, Julia Andrys ${ }^{4}$, and Matthew R. Hipsey ${ }^{1,2}$ \\ ${ }^{1}$ Aquatic Ecodynamics, UWA School of Agriculture and Environment, \\ The University of Western Australia, Crawley, WA 6009, Australia \\ ${ }^{2}$ UWA Oceans Institute, The University of Western Australia, Crawley, WA 6009, Australia \\ ${ }^{3}$ Water Science Branch, Department of Water and Environmental Regulation, Perth, WA 6842, Australia \\ ${ }^{4}$ Environmental and Conservation Sciences, Murdoch University, Murdoch, WA 6015, Australia
}

Correspondence: Peisheng Huang (peisheng.huang@uwa.edu.au)

Received: 13 April 2020 - Discussion started: 5 June 2020

Revised: 23 September 2020 - Accepted: 2 October 2020 - Published: 27 November 2020

\begin{abstract}
Ecosystems in shallow micro-tidal lagoons are particularly sensitive to hydrologic changes. Lagoons are complex transitional ecosystems between land and sea, and the signals of direct human disturbance can be confounded by variability of the climate system, but from an effective estuary management perspective, the effects of climate versus direct human engineering interventions need to be identified separately. This study developed a 3D finite-volume hydrodynamic model to assess changes in hydrodynamics of the Peel-Harvey Estuary, a large shallow lagoon with restricted connection with ocean; this was done by considering how attributes such as water retention time, salinity and stratification have responded to a range of factors, focusing on the drying climate trend and the opening of a large artificial channel over the period from 1970 to 2016, and how they will evolve under current climate projections. The results show that the introduction of the artificial channel has fundamentally modified the flushing and mixing within the lagoon, and the drying climate has changed the hydrology by comparable magnitudes to that of the opening of the artificial channel. The results also highlight the complexity of their interacting impacts. Firstly, the artificial channel successfully improved the estuary flushing by reducing average water ages by $20-110 \mathrm{~d}$, while in contrast the reduced precipitation and catchment inflow had a gradual opposite effect on the water ages; during the wet season this has almost counteracted the reduction brought about by the channel. Secondly, the drying climate caused an increase in the salinity of the lagoon by 10-30 PSU (Practical Salinity Unit); whilst the ar-
\end{abstract}

tificial channel increased the salinity during the wet season, it has reduced the likelihood of hypersalinity ( $>40$ PSU) during the dry season in some areas. The opening of the artificial channel was also shown to increase the seawater fluxes and salinity stratification, while the drying climate acted to reduce the salinity stratification in the main body of the estuary. The impacts also varied spatially in this large lagoon. The southern estuary, which has the least connection with the ocean through the natural channel, is the most sensitive to climate change and the opening of the artificial channel. The projected future drying climate is shown to slightly increase the retention time and salinity in the lagoon and increase the hypersalinity risk in the rivers. The significance of these changes for nutrient retention and estuary ecology are discussed, highlighting the importance of these factors when setting up monitoring programmes, environmental flow strategies and nutrient load reduction targets.

\section{Introduction}

Hydrologic features such as water circulation and retention, as well as the pattern of saline water intrusion, are critical in shaping estuarine ecosystems. The interactions between freshwater runoff pulses with ocean water can create complex hydrodynamics that subsequently structure coastal biogeochemical processes, including the distributions of sediment and nutrients, and areas favourable for primary productivity (e.g. Legović et al., 1994; Kasai et al., 2010; Watanabe 
et al., 2014; Cloern et al., 2017). Whilst nutrient loads are the primary determinant affecting the long-term trophic state of coastal waters (Howarth and Marino, 2006; Williamson et al., 2017), the timescales associated with water retention and mixing are critical in mediating the relationship between nutrient inputs and the ensuing water quality response, including the likelihood of nuisance algal blooms or hypoxia (e.g. Knoppers et al., 1991; Ferreira et al., 2005; Paerl et al., 2006; Zhu et al., 2017). The retention of water and hydrodynamic patterns that emerge in any given site are largely dependent upon local geomorphological features, though increasingly coastal engineering and changes in river hydrology disturb natural patterns of water exchange (Knoppers et al., 1991; Kjerfve et al., 1996; Dufour et al., 2001; Gong et al., 2008; Odebrecht et al., 2015; Almroth-Rosell et al., 2016). Understanding and predicting these hydrologic changes are critical to underpin adaptive approaches to estuary water quality management and ecological restoration.

Coastal lagoons and embayments with low rates of ocean exchange are particularly sensitive relative to other estuary forms. The typical low flushing rates lead to high rates of deposition of sediment and particulate matter and accumulation of nutrients (e.g. Newton et al., 2014, 2018; Paerl et al., 2014). They are also productive ecosystems and often experience conflicting interests between the ecosystem services they provide and the pressures from urban development and agricultural expansion (Petersen et al., 2008; Zaldívar et al., 2008; Pérez-Ruzafa et al., 2011; Basset et al., 2013; Newton et al., 2014). In most cases, salt intrusion mediates lagoon salinity and drives a difference between the surface and bottom salinity (salinity stratification). In highly seasonal systems this effect leads to notable oxygen depletion and establishes hypoxia in the bottom boundary layer (Bruce et al., 2014; Cottingham et al., 2014; Huang et al., 2018). In Mediterranean climate regions, further concerns of hypersalinity through evaporation during the long dry summer and autumn months also exist (Potter et al., 2010). As a result, the hydrodynamics of coastal lagoons are frequently modified by the creation of artificial channels built to enhance hydrologic connectivity to the ocean and increase nutrient export (e.g. Breardley, 2005; Manda et al., 2014; Prestrelo and Monteiro-Neto, 2016), or they are indirectly modified by engineering projects associated with dredging and coastal management (e.g. Ghezzo et al., 2010; Sahu et al., 2014).

Changes in lagoon hydrology result from variability in river flows and meteorological and ocean conditions, alongside (sporadic) human interventions associated with coastal engineering developments. Globally, many studies have shown that coastal lagoon systems are vulnerable to climate change, including the factors from reduced flow and/or sea level rise (Nicholls and Hoozemans, 1996; Nicholls et al., 1999; Scavia et al., 2002; Chapman, 2012; Newton et al., 2014; Umgiesser et al., 2014). In particular, shallow coastal lagoons respond quickly to the ocean and catchment inputs, whilst their geomorphological characteristics (bathymetry and especially the configuration of their inlets with the open sea) affect their hydrodynamics, including circulation patterns, flushing time and water mixing (e.g. Smith, 1994; Spaulding, 1994; Koutitonsky, 2005; Umgiesser et al., 2014). This attribute has meant that these systems therefore amplify the salinity and temperature changes expected from climate change relative to the open sea, and they can serve as sentinel systems for global change studies (Ferrarin et al., 2014). On the other hand, anthropogenic activities introduce hydrological modifications associated with water resource management (e.g. Hollis, 1990; Kingsford et al., 2006; Gong et al., 2008) and engineering modifications (Ghezzo et al., 2010; García-Oliva et al., 2018). Among which, the opening of artificial channels in lagoon systems has been a popular measure to enhance ocean connectivity, but this activity has the effect to fundamentally alter the hydrology and aquatic communities (e.g. Lord, 1998; Manda et al., 2014; Prestrelo and Monteiro-Neto, 2016; García-Oliva et al., 2018). Changes in the connection of restricted lagoons with the ocean can exhibit a marked change in the salinity pattern or the extent of hypersaline conditions (Kjerfve, 1994; Gamito et al., 2005 ) and subsequently influence the ecosystem within these lagoons (Gamito, 2006; García-Oliva et al., 2018). These changes motivate us to assess lagoon hydrology in order to predict impacts and implement mitigation measures that also account for climate influence. However, tracking the longterm changes in hydrology remains an ongoing challenge since the signals of human disturbance are often confounded by variability of the climate system and lost in the dynamic estuarine conditions (Feyrer et al., 2015; Cloern et al., 2016). With the interacting effects of human interventions in conjunction with climate change, trends are not necessarily easy to predict. For example, the opening of an artificial channel and a drying climate can both introduce more ocean water into an estuary. On the other hand, the drying climate enhances water residence time, which may cancel out flushing benefits from the artificial channel. The combined effects are further complicated in large lagoon-type estuaries with complex morphology, where complicated patterns of water retention and stratification can develop (e.g. Ferrarin et al., 2013). From a lagoon management perspective, it is necessary to attribute the impacts from climate and human activity factors to better plan the necessary estuary and catchment management activities, including adaptation strategies associated with nutrient load targets and, in some cases, environmental water provision.

Here we explore these ideas through reconstruction of the long-term hydrologic evolution of a large estuarine lagoon in Western Australia: the Peel-Harvey Estuary (PHE). The PHE system has been subject to both a notable drying climate trend and substantial coastal modification in the form of the opening of a large artificial channel, coastal development and dredging. The artificial channel, termed the "Dawesville Cut" (hereafter referred to as "the Cut"), was built in 1994 with the purpose of increasing flushing and reducing nu- 
trient concentrations. In parallel, the impact on inland water resources of recent climate trends has been particularly acute in the PHE catchment, which was acknowledged by the IPCC AR4 (IPCC Fourth Assessment Report), identifying this region as one amongst those that have experienced the greatest impact on divertible water resources in the world (Izrael et al., 2007; Bates et al., 2008). From the 1970s, rainfall has decreased by $16 \%$ and streamflows have declined by more than $50 \%$, a trend which has appeared to accelerate since the 2000s (Silberstein et al., 2012). Whilst the nutrient and phytoplankton concentrations have been successfully reduced by the construction of the channel (Brearley, 2005), the long-term river flows have shown a clear trend of decreasing inputs to the estuary with concerns for the conditions of the tidal riverine portions of the system (Gillanders et al., 2011; Hallett et al., 2018). A series of water quality improvement plans (e.g. Environmental Protection Authority, 2008; Rogers et al., 2010) continue to be developed to promote estuary health; however, ongoing concerns about the current and future water quality and ecologic conditions of the system (Valesini et al., 2019) require knowledge of spatio-temporal changes in water retention, stratification and salinization to support adaptation efforts.

It is therefore the aim of this study to develop a methodology to disentangle drivers of change of the PHE system, over the period from 1970 to 2016, and outline the expected future trajectory of lagoon conditions. To this end, we employ a three-dimensional finite-volume hydrodynamic model for analysis of environmental drivers on estuarine hydrology by comparing current and counter-factual modelling scenarios to enable attribution of the drivers of change. To enable the long-term reconstruction of the model simulations for periods before the instrument record (and for future conditions), we drive the model with a hybrid set of weather and hydrological boundary condition data from observations and supporting models. The results of simulations are presented to analyse the sensitivity of water retention time, salinity and stratification within the lagoon to selected factors. By untangling the effect of the drying climate versus the Cut opening (through time and space), we explore the results through the lens of nutrient load reduction targets and biodiversity management implications. We anticipate that the approach adopted here can be useful to assist in the climate change adaptation efforts for other estuarine lagoons in mid-latitude regions.

\section{Methods}

\subsection{Site description}

PHE is a large shallow coastal estuary-lagoon system located approximately $75 \mathrm{~km}$ south of Perth in Western Australia (Fig. 1), which is listed under the Ramsar convention for wetlands of international significance. The estuary has a
Table 1. Principal tidal constituents for Fremantle tide record from 1970 to 2017.

\begin{tabular}{lrrcc}
\hline Constituents & $\begin{array}{r}\text { Potential } \\
\text { energy } \\
(\%)\end{array}$ & $\begin{array}{r}\text { Amplitude } \\
(\mathrm{m})\end{array}$ & $\begin{array}{r}\text { Greenwich } \\
\text { phase lag } \\
\text { (degrees) }\end{array}$ & $\begin{array}{r}\text { Frequency } \\
\text { (cycles } \\
\text { per hour) }\end{array}$ \\
\hline K1 & 61.08 & 0.156 & 324 & 0.0418 \\
O1 & 25.95 & 0.101 & 308 & 0.0387 \\
P1 & 6.06 & 0.049 & 314 & 0.0416 \\
M2 & 3.53 & 0.0374 & 323 & 0.0805 \\
S2 & 3.37 & 0.0365 & 334 & 0.0833 \\
\hline
\end{tabular}

complex morphometry and comprises two shallow lagoons: one is the Peel Inlet, a circular inlet to the north, and the other is the Harvey estuary, an oblong lagoon attached to the Peel Inlet at its northeastern edge, with a combined area of approximately $133 \mathrm{~km}^{2}$. The estuary connects to the ocean via two channels: (1) the Mandurah Channel, a natural but narrow $5 \mathrm{~km}$ long channel with water depths varying between 2 and $5 \mathrm{~m}$, and (2) the Cut, an artificial channel of about $2.5 \mathrm{~km}$ long, $200 \mathrm{~m}$ wide and between 3 and $6.5 \mathrm{~m}$ deep, built in 1994 (Bicknell, 2006; Environmental Protection Authority, 2008). The system experiences a Mediterranean-type climate characterized by a strong seasonal pattern of cool wet winters and hot dry summers, with almost all of the annual rainfall occurring during the cooler months of May to October (Gentilli, 1971; Finlayson and McMahon, 1988).

The estuary experiences a micro-tidal regime, with a range $<1 \mathrm{~m}$. The tide is dominated by the lunar diurnal constituents $(\mathrm{K} 1, \mathrm{O} 1)$ contributing $87 \%$ of the tide potential energy, followed by the solar diurnal constituent (P1), principal lunar semidiurnal constituent (M2) and principal solar semidiurnal constituent (S2) (Table 1). The coastal catchment of the estuary is drained by three major river systems: the Serpentine, Murray and Harvey rivers (on average contributing $16.4 \%, 46.5 \%$ and $30.8 \%$ to the total flow, respectively), as well as numerous minor drains (contributing $6.3 \%$ to the total flow) (Kelsey et al., 2011).

\subsection{Modelling approach}

\subsubsection{Hydrodynamic modelling platform and numerical methods}

The TUFLOW-FV (BMT WBM, 2013) hydrodynamic model was adopted, using a flexible-mesh (finite-volume) approach to resolve the variations in water level, horizontal salinity distribution and vertical density stratification in response to tides, inflows and surface thermodynamics. The mesh consists of triangular and quadrilateral elements of different sizes that are suited to simulating areas of complex estuarine morphometry. To meet accuracy requirements, a fine grid resolution (mean mesh area $\sim 12000 \mathrm{~m}^{2}$ ) was used within the lagoons and a coarse resolution was implemented towards the ocean boundary. The vertical mesh discretization 

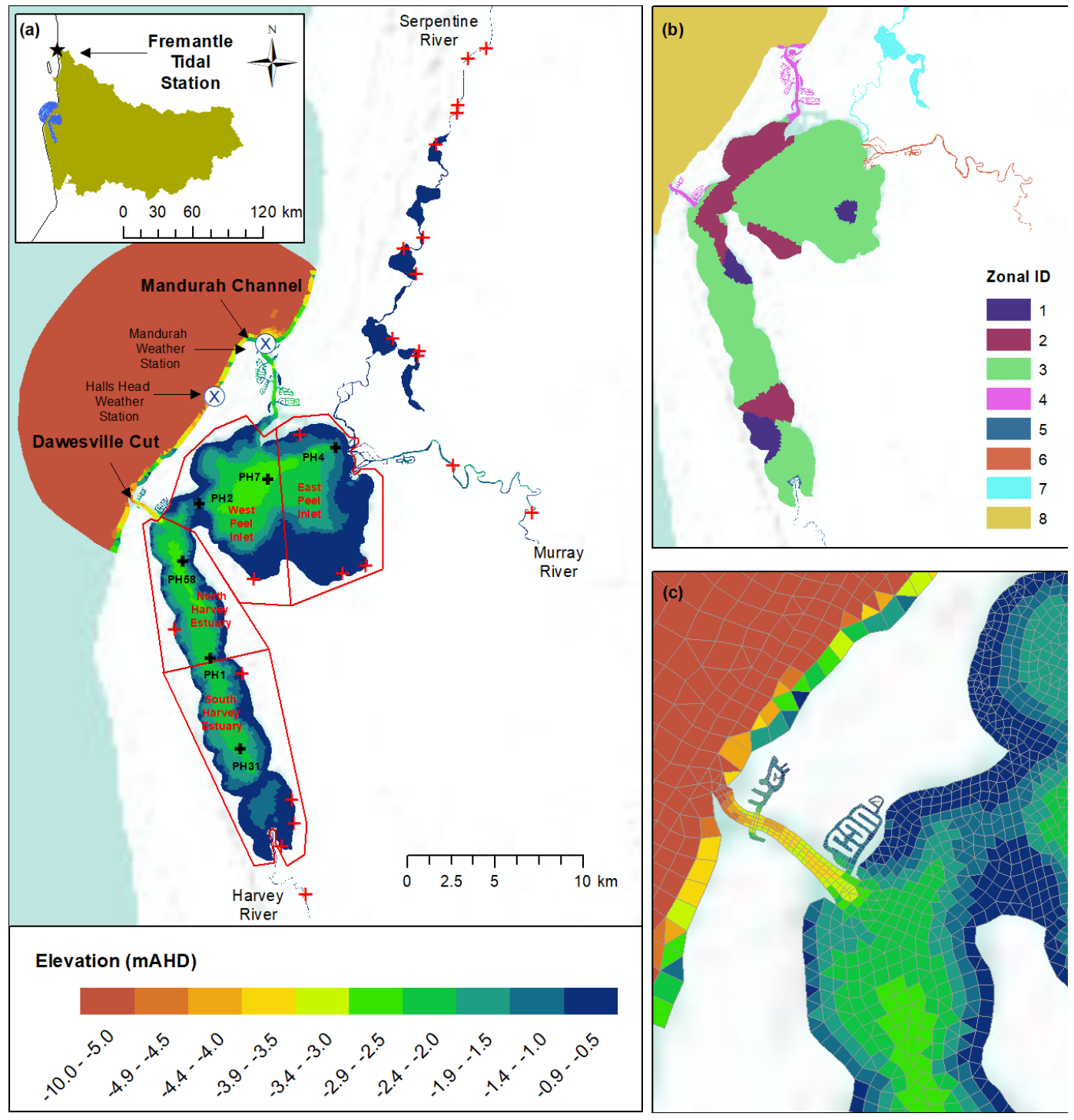

Figure 1. (a) Model domain of the Peel-Harvey Estuary and three main rivers: Serpentine River, Murray River and Harvey River; the tidal portion of each is depicted up to the gauge location. The colours indicate the water depths of the study domain in units of the Australian Height Datum (AHD); the black crosses within the estuary indicate the locations of six monitoring sites; the red crosses indicate the locations of ungauged flows entering the main rivers and estuary; the blue crosses indicate the location of weather stations; and the red polygons indicate the areas for analysis results. (b) Zonal categorization of the model domain according to the area and aquatic vegetation biomass (see Table 2); (c) a zoom-in view of the artificial channel Dawesville Cut, constructed in 1994 to improve ocean flushing.

adopted a hybrid $\sigma-z$ coordinate allowing multiple surface Lagrangian layers to respond to tidal elevation changes. The layer thickness was $0.2 \mathrm{~m}$ at depths of $1.0-5.0 \mathrm{~m}$ that gradually increased to $0.5 \mathrm{~m}$ in deeper water, and then five uniformly distributed sigma layers were added above the fixedthickness layers. The finite-volume numerical scheme solves the conservative integral form of the non-linear shallow water equations in addition to the advection and transport of scalar constituents such as salinity and temperature. The equations are solved in 3D with baroclinic coupling from both salinity and temperature using the UNESCO equation of state
(Fofonoff and Millard, 1983). The water level at the ocean boundary was specified with the record (every $15 \mathrm{~min}$ ) from the Fremantle gauge station located about $52 \mathrm{~km}$ to the north of the study site, while the velocity was calculated internally based on a radiation condition assumption.

Surface momentum exchange and heat dynamics are solved internally within TUFLOW-FV. In the current application, turbulent mixing of momentum and scalars has been calculated using the Smagorinsky scheme in the horizontal plane and through coupling with the General Ocean Turbulence Model (GOTM) for vertical mixing. The bottom shear 
stress was calculated using a roughness-length relationship assuming a rough-turbulent logarithmic velocity profile in the lowest model layer. The roughness length, $z_{0}$, settings were based on the area type (e.g. coast, rivers and estuary) and the estimated biomass of aquatic vegetation within the cell. For this purpose, the bottom was categorized into eight zones (Fig. 1b) where the benthic characteristics and associated $z_{0}$ in each zone were specified (Table 2). While the setting of $z_{0}$ affects the water advection, and uncertainty remains in the spatial (and temporal) variability in $z_{0}$, it is important to note that the modelled water age and salinity do not change fundamentally over a reasonable range of $z_{0}$, as shown in the results of the model sensitivity tests described later.

Multiple concepts of hydrodynamic time parameters (flushing time, residence time, water age, export time, etc.) have been used in coastal hydrology research, and each of these parameters are different in their definition and application (e.g. Monsen et al., 2002; Jouon et al., 2006; Sheldon and Alber, 2006). This study employed a few hydrodynamic time parameters to serve for different study purposes. The first time parameter was the "water age", which was defined as the time the water had spent since entering the estuary through the boundaries (either the ocean or rivers), and it was computed in each computational cell as a conservative tracer subject to a constant increase with time ("ageing") and mixing (Li et al., 2019) as

$\mathrm{d} \tau / \mathrm{d} t=1$,

where $\tau$ is the water age and $t$ is the time, with settings of initial water age set to 0 throughout the estuary and water age of 0 set on the seaward and freshwater boundaries. This method provided the temporal and spatial variation in water retention, where $\tau=\tau(x, y, z, t)$. This water age method is considered to have the advantage of presenting the spatial heterogeneity of water retention (Monsen et al., 2002) and is suitable for long-term hydrology simulations; it is employed in this study to investigate the long-term evolution of water retention characteristics.

Secondly, the hydrodynamic time parameters of water flushing time (WFT) and water renewal time (WRT) were used to investigate the changes in the mixing efficiency (ME) due to the changes in the ocean connectivity by the opening of the artificial channel and the changes in catchment inflows. WFT is a bulk basin-wide water flushing timescale, defined as

$\mathrm{WFT}=V / Q$,

where $V$ is the total estuary volume and $Q$ is the water flux flowing out of the system. The WRT is defined as the time required for each cell of the lagoon domain to replace the originally released conservative tracer, with settings of initial tracer concentration set to 1 uniformly throughout the estuary and a concentration of zero imposed on the inlets and freshwater boundaries.
After WFT and WRT are calculated, the ME can be obtained as the ratio between WFT and WRT. ME ranges between 0 and 1 . In the theoretical case of $\mathrm{ME}=1$, the estuary is considered a fully mixed system, while $\mathrm{ME}=0$ indicates there is no mixing of water masses entering the estuary with the inner waters. The ME is a useful index for investigating the mixing behaviour of the lagoons and also for intercomparison and classification of their ocean connection types (Umgiesser et al., 2014); it was employed to investigate the impact of the Cut opening and catchment inflows on the estuary mixing.

\subsubsection{Model calibration, performance evaluation and sensitivity tests}

The model was calibrated with a structured hierarchical approach, similar to those described in Muleta and Nicklow (2004) and Hipsey et al. (2020). This approach first identified the key parameters of importance to the hydrology in the current study based on literature review and prior expert knowledge. In this stage, the key parameters were identified to be the bottom drag coefficient, the bulk aerodynamic coefficients and the mixing scheme options associated with the vertical turbulence model (in this case this is parameterized through the GOTM plugin), as well as the bulk transfer coefficient for latent heat flux. In the second stage, a matrix of simulations, each with predetermined parameter vectors and model options, was assessed against the observed salinity and temperature data at six stations within the estuary (Fig. 1, at both surface and bottom levels), and the water elevation at the centre of the Peel Inlet in year 1998, which presented a year with median rainfall and catchment inflows. The capability of the model to reproduce the salinity stratification (magnitude of difference between the surface and bottom salinity) created by the interaction of ocean intrusion and freshwater runoff during the wet season was also considered in the model calibration. Based on the calibration results, a $k-\varepsilon$ mixing scheme, a linear model for the aerodynamic coefficients (Wu, 1982), a bulk transfer coefficient for latent heat flux of 0.0013 and the roughness scales as in Table 2 were selected. After calibration, the model was then validated with salinity and temperature data in all simulated years (except 1970 when the monitored data at six stations were not available). For each variable, we evaluated the model quantitatively against the monitored data using three skill metrics: correlation coefficient $(r)$, mean absolute error (MAE) and model skill score (SS). The validation results suggest that the model captured the major features of the hydrodynamic response to the external drivers of the tide and freshwater inputs, and the model satisfactorily reproduced the salinity and temperature in both the surface and bottom. A full description of the calibration and validation results is given in the Supplement.

The current study focused on the impact of reduced inflow, due to the drying climate and the Cut, on the estuary 
Table 2. Zonal characteristics and roughness length setting $\left(z_{0}\right)$ in the model domain.

\begin{tabular}{llrr}
\hline $\begin{array}{l}\text { Zonal } \\
\text { ID }\end{array}$ & Areas & $\begin{array}{r}\text { Aquatic } \\
\text { vegetation } \\
\text { biomass }\end{array}$ & $z_{0}$ \\
& & $\begin{array}{r}\text { (g dry weight } \\
\text { per }{ }^{2} \text { ) }\end{array}$ & \\
& & $100-230$ & 0.03 \\
& & $50-100$ & 0.02 \\
1 & South/North Harvey Estuary, East Peel Inlet & $0-50$ & 0.01 \\
2 & South/North Harvey Estuary, West Peel Inlet & $\sim 0$ & 0.003 \\
3 & Harvey Estuary and Peel Inlet & $\sim 0$ & 0.003 \\
4 & Dawesville Cut & $\sim 0$ & 0.003 \\
5 & Harvey River & $\sim 0$ & 0.003 \\
6 & Murray River & $\sim 0$ & 0.002 \\
7 & Serpentine River & & \\
8 & Coastal ocean & & \\
\hline
\end{tabular}

hydrology. However, the perturbations of environmental factors such as air temperature, tidal elevation and benthic vegetation could also affect the local hydrology, and so their influence on the modelling results was explored. To evaluate the effects of these factors, the sensitivity of $\tau$ and salinity was assessed relative to changes in (1) air temperature $\left( \pm 1^{\circ}\right.$, representing 100-year change of local air temperature), (2) tidal elevation $( \pm 0.15 \mathrm{~m}$, representing 100-year change of local tide record) and (3) bed roughness length $( \pm 50 \%$, representing $50 \%$ change of bed roughness). The ranges of these environmental factors were carefully selected based on the historical records. Two years, 1990 and 1998, representing a year before the Cut opening and another year with the Cut open, respectively, were selected for these model sensitivity tests. Detailed results from the sensitivity assessment are also included in the Supplement. In summary, the modelled salinity and $\tau$ were shown to be affected by changes in the mean sea level and bottom roughness variations, but the effects of these factors on the results were small when compared to that caused by the reduced flow over the past decades and the Cut opening (shown in the next section). For example, the maximum change in $\tau$ observed in the sensitivity test runs was $8.6 \mathrm{~d}$, caused by the enhanced bottom roughness in the 1990 scenario, compared to the magnitude of 20$100 \mathrm{~d}$ caused by the reduced flow from 1970 to 2016 (see more details below). The maximum changes in the salinity observed in the sensitivity test runs was $2.8 \mathrm{PSU}$, caused by the reduction of tide level in the Harvey Estuary, compared to the magnitude of 10-30 PSU changes in the salinity caused by the reduced flows from 1970 to 2016 (see more details below). These results suggested the changes in the climate and the ocean connectivity are the major drivers of the hydrology of the Peel-Harvey Estuary.

\subsubsection{Climate change context and simulation rationale}

Historical observations of nearby precipitation and the gauged data of the major Murray River inflow have shown a decreasing trend from 1970 to the present (Fig. 2), though variability from year to year is noticeable. The average annual precipitation has declined by $15 \%$ when comparing the period 1994-2016 relative to 1970-1993, and this led to a dramatic decrease in annual inflow volumes, which is most notable in the past decade.

Years with inflow rates close to the 10 -year moving average were selected for hydrologic modelling simulations to explore in more detail the hydrologic changes occurring within these years (depicted relative to the trend in Fig. 2b). Due to the concern that the drying climate will continue into the 21st century (Silberstein et al., 2012; Smith and Power, 2014), we also undertook model simulations to investigate potential hydrologic changes under future conditions representative of 2040 and 2060 by considering reduced streamflow and rising sea levels. The runoff declines were based on the mean projection by Smith and Power (2014) that suggested the total runoff to the rivers and estuaries within the southwest Western Australia region will drop by about $0.96 \%$ per year, corresponding to the projected reduction in precipitation of $0.27 \%$ per year, on average. Sea level rise was also included in the future scenarios, estimated from the long-term (1897-2000) tide gauge observations at the Fremantle tide gauge station that shows a sea level trend of $1.50 \mathrm{~mm} \mathrm{yr}^{-1}$ (Kuhn et al., 2011). These estimates may be biased due to a possible accelerated sea level rise towards the end of the 21st century (IPCC, 2007; Kuhn et al., 2011), but we highlight that these future scenarios were set up to investigate the changing hydrology into a future from the projected drying climate trend.

For each selected year, the modelling simulation started from 1 September of the previous year, giving a 4-month spin-up period, and the results from 1 January to the end of the selected year were used for analysis. The initial conditions of water temperature and salinity were interpolated from the field data when they were available (years 19852016), except the year 1970 when no field data were available and 1978 when field data at sites PH31 and PH58 were 
(a) annual precipitation

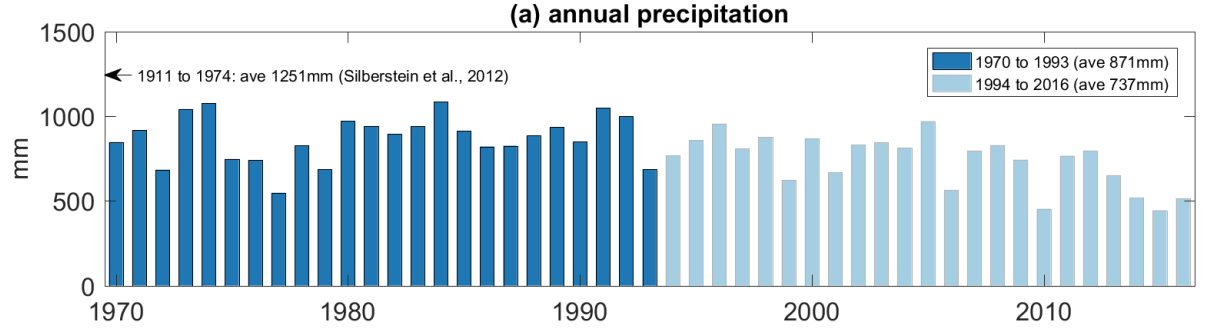

(b) Murray River annual inflow

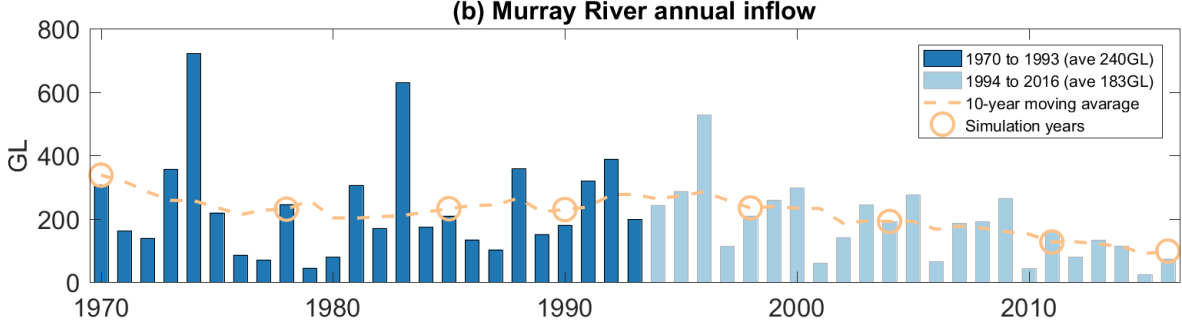

(c) sea level

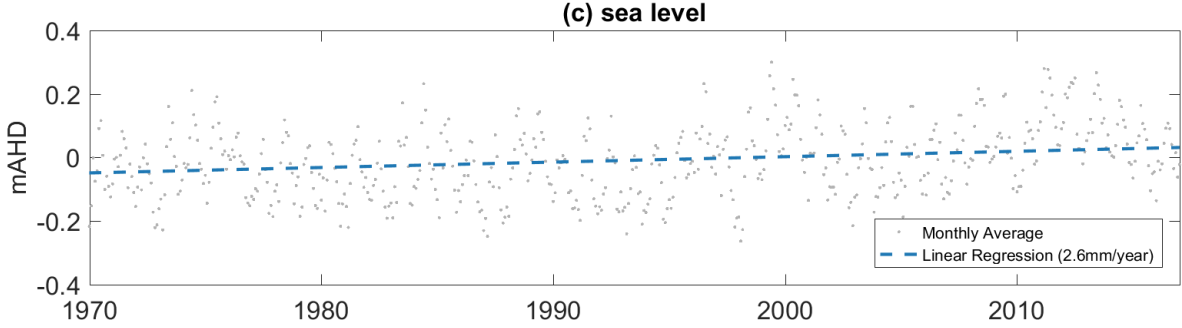

(d) salinity in Harvey Estuary $(\cdot)$ and Peel Inlet $(x)$

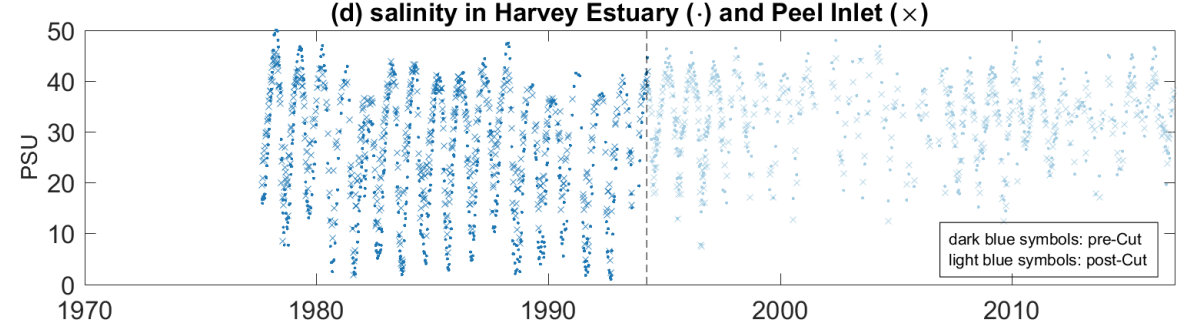

(e) TCHLA in Harvey Estuary $(\cdot)$ and Peel Inlet $(x)$

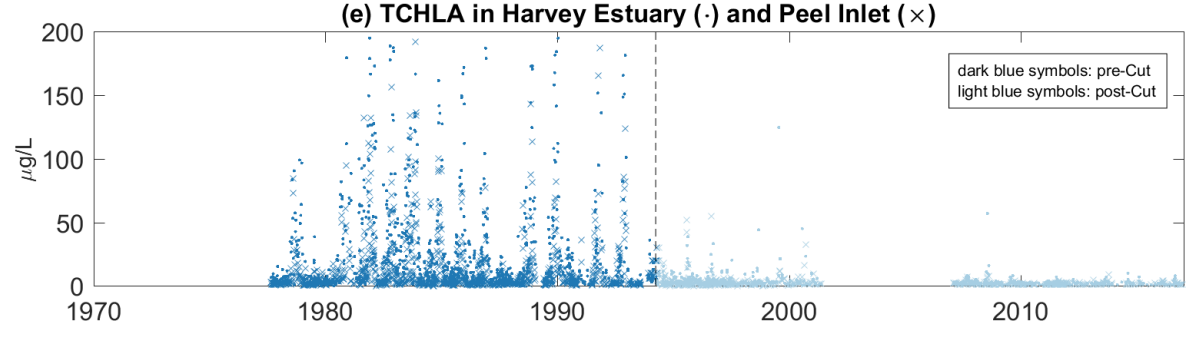

Figure 2. Historical record of (a) annual precipitation rate, (b) Murray River annual inflow rate, (c) monthly-average sea level at Fremantle gauge station, (d) salinity at Harvey Estuary and Peel Inlet, and (e) total chlorophyll $a$ (TCHLA) in Harvey Estuary and Peel Inlet since 1970 to 2016.

missing, so the same initial conditions as for 1985 were adopted. For the future scenarios, the same initial conditions as in 2016 were used.

For the modelling years after 1994, when the artificial channel was constructed, we also ran "no-Cut" counterfactual scenarios, which assumed the Dawesville Cut engineering intervention was not constructed, in order to separate the impact of the artificial channel on hydrology relative to the "with-Cut" scenarios (Table 3).

Gauged flow rate data for the Murray River, Serpentine River and Harvey River data were applied to the hydrodynamic model whenever they are available. Gauged flow rate data for Murray River were available from 1970 to the present, while for Serpentine River and Harvey River were available from 1982 to present. For the missing periods in the 
Table 3. Summary of simulated scenarios and their annual precipitation, catchment inflow volumes, mean sea level and Cut-opening information.

\begin{tabular}{|c|c|c|c|c|c|c|}
\hline $\begin{array}{l}\text { Simulation } \\
\text { category }\end{array}$ & $\begin{array}{c}\text { Simulated } \\
\text { year }\end{array}$ & $\begin{array}{c}\text { Annual } \\
\text { precipitation } \\
\left(\mathrm{mm} \mathrm{yr}^{-1}\right)\end{array}$ & $\begin{array}{c}\text { Annual } \\
\text { catchment } \\
\text { inflow } \\
\left(\times 10^{6} \mathrm{~m}^{3} \mathrm{yr}^{-1}\right)\end{array}$ & $\begin{array}{r}\text { Annual } \\
\text { mean sea } \\
\text { level } \\
(\mathrm{m} \text { AHD })\end{array}$ & $\begin{array}{l}\text { Cut } \\
\text { opening }\end{array}$ & $\begin{array}{c}\text { Sensitivity } \\
\text { tests }\end{array}$ \\
\hline \multirow[t]{4}{*}{ Pre-Cut years } & 1970 & 846.4 & 705.9 & -0.043 & No & \\
\hline & 1978 & 827.5 & 591.6 & -0.024 & No & \\
\hline & 1985 & 911.7 & 564.0 & -0.033 & No & \\
\hline & 1990 & 849.2 & 515.8 & -0.071 & No & Yes \\
\hline \multirow[t]{4}{*}{ Post-Cut years } & 1998 & 876.2 & 490.4 & -0.027 & Yes & Yes \\
\hline & 2004 & 813.7 & 478.0 & -0.027 & Yes & \\
\hline & 2011 & 766.0 & 378.9 & 0.156 & Yes & \\
\hline & 2016 & 514.4 & 244.2 & 0.017 & Yes & \\
\hline \multirow[t]{4}{*}{ No-Cut scenarios } & 1998 & 876.2 & 490.4 & -0.027 & No & \\
\hline & 2004 & 813.7 & 478.0 & -0.027 & No & \\
\hline & 2011 & 766.0 & 378.9 & 0.156 & No & \\
\hline & 2016 & 514.4 & 244.2 & 0.017 & No & \\
\hline \multirow[t]{4}{*}{ Future scenarios } & 2040 & 481.1 & 187.9 & 0.053 & Yes & \\
\hline & 2060 & 453.3 & 138.9 & 0.083 & Yes & \\
\hline & 2040 & 481.1 & 187.9 & 0.053 & No & \\
\hline & 2060 & 453.3 & 138.9 & 0.083 & No & \\
\hline
\end{tabular}

gauged flows and the ungauged drains, the output from the SOURCE $\left(\mathrm{eWater}^{\circledR}\right)$ catchment modelling platform (Kelsey et al., 2011; Welsh et al., 2013), operated by the Western Australia Department of Water and Environmental Regulation, was used to estimate flows by carefully comparing the measured and modelled flow data. Groundwater inputs were previously estimated to represent only $\sim 1 \%$ of total water inputs (Black and Rosher, 1980) and were therefore not included in the modelling simulations.

Various data sources were used to set up meteorological inputs due to the study period spanning back to 1970 , when meteorological observations were not routinely available across the modelling domain at hourly frequencies. The first data source was the local Mandurah weather station located beside the natural channel of the estuary (Fig. 1). This dataset provided hourly records since 2001 . The hourly fields over the period 1981-2000 were obtained from regional climate model simulations for Southwest Australia at a $5 \mathrm{~km}$ resolution (Andrys et al., 2015; Kala et al., 2015), which were carried out using the Weather Research and Forecasting (WRF) model, one of the most widely used regional climate models. Andrys et al. (2015) showed that the WRF model was able to adequately simulate the climate of southwestern Australia, and these simulations have also been used to assess the impacts of current and future climate on temperature and precipitation (Andrys et al., 2016, 2017) as well as climate indices relevant to viticulture for southwestern Australia (Firth et al., 2017). The WRF simulations of Andrys et al. (2015) have also been benchmarked against other re- gional climate model simulations across the Australian continent and have shown to perform well in simulating both temperature and precipitation (Di Virgilio et al., 2019) as well as heat-wave events (Hirsch et al., 2019). For the years before 1981, the weather conditions measured at the nearby Halls Head weather station $(4.2 \mathrm{~km}$ away from the Mandurah station) were used. Although various sources of climate data were used, the wind regimes of these data sources showed a similar distribution in wind magnitudes and directions (Fig. 3). The winds in the Mandurah station record are relatively smaller when compared to the other two sources; however, this difference may be due to the natural variation in the climate and are not expected to change the main hydrological features in the lagoon.

A summary of all historical simulations and future scenarios is provided in Table 3. The total inflow into the estuary of the chosen simulation years shows a general decrease from past to future, except for the year 1978 when the total inflow rate was less than that in 1985 and 1990 . This was due to an exceptionally low inflow rate within the Harvey River, produced from the catchment model output, which had an effect mostly on the Harvey Estuary. We still include this year to show the historical evolution during the past decades. 
(a) $1970-1980$

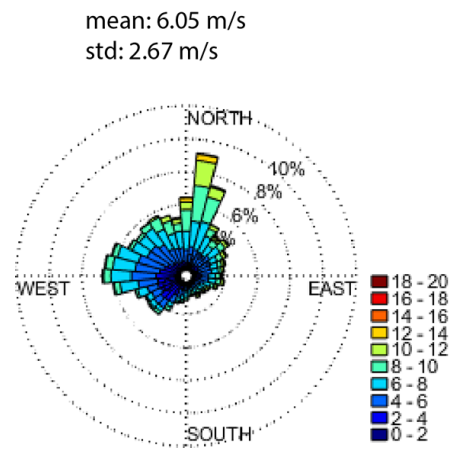

(b) $1981-2000$

mean: $6.28 \mathrm{~m} / \mathrm{s}$ std: $2.84 \mathrm{~m} / \mathrm{s}$

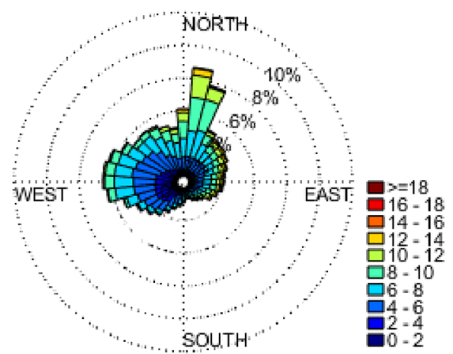

(c) $2001-2016$

mean: $5.38 \mathrm{~m} / \mathrm{s}$ std: $2.83 \mathrm{~m} / \mathrm{s}$

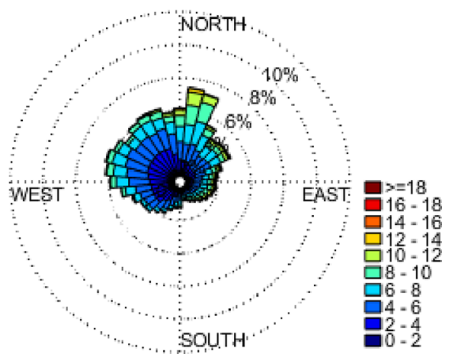

Figure 3. Rose plot of wind condition in years of (a) 1970-1980, obtained from the Halls Head weather station; (b) 1981-2000, obtained from the WRF weather model; and (c) 2001-2016, obtained from the Mandurah weather station.
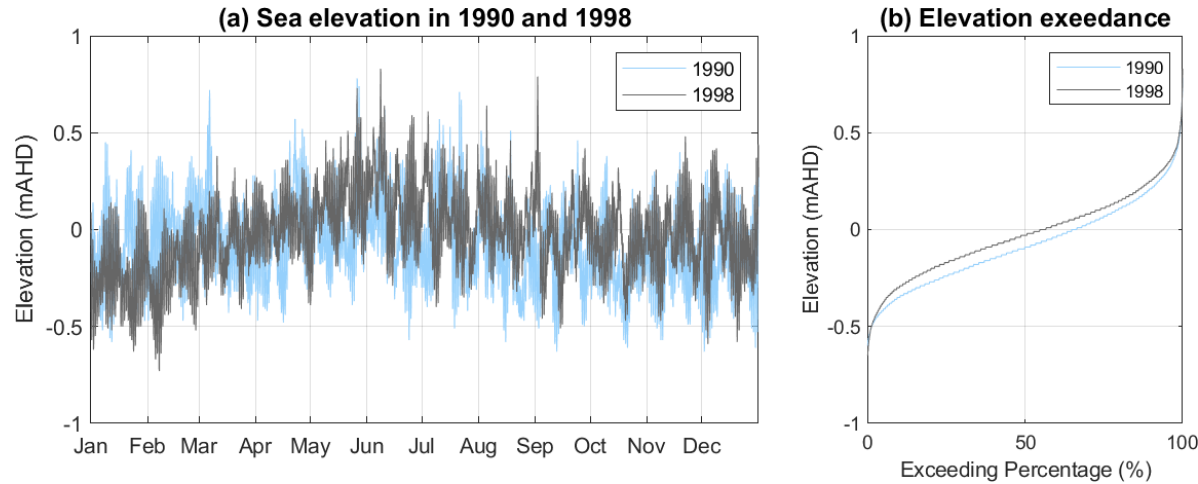

Figure 4. (a) Sea level changes and (b) their exceedance plot in the years 1990 and 1998.

\section{Results}

\subsection{Estuary response to the change in ocean connectivity}

The impact of the changes in ocean connectivity due to the construction of the artificial channel on the estuary hydrology was first investigated by analysing the observed and modelled salinity and temperature at the centre of the two lagoons, as well as the surface elevation within the Peel Inlet, in the years of 1990 (representing a "pre-Cut" year) and 1998 (representing a "post-Cut" year). These 2 years were compared because they have similar annual precipitation and catchment inflow rates (Table 3 ) and tidal forcing characteristics in terms of the annual mean sea level and tidal range (Table 4, Fig. 4). Therefore, the comparison provided a valuable insight into the impacts of the artificial channel on the estuary environment.

The monitored and modelled salinity and temperature at the centres of the two lagoons demonstrate the changes in the seasonal cycle in response to the catchment inflows and the Cut opening, as well as the model's capability to capture these changes (Fig. 5). In summer and early autumn the flow
Table 4. Comparison of principal tidal constituents in years 1990 and 1998.

\begin{tabular}{lrrrrr}
\hline Constituents & \multicolumn{2}{c}{ Potential energy $(\%)$} & & \multicolumn{2}{c}{ Amplitude $(\mathrm{m})$} \\
\cline { 2 - 3 } \cline { 6 - 6 } & 1990 & 1998 & & 1990 & 1998 \\
\hline K1 & 57.19 & 56.79 & & 0.159 & 0.156 \\
O1 & 30.28 & 30.05 & & 0.115 & 0.114 \\
P1 & 5.45 & 5.66 & & 0.0490 & 0.0494 \\
M2 & 3.92 & 4.31 & & 0.0415 & 0.0431 \\
S2 & 3.16 & 3.20 & & 0.0373 & 0.0371 \\
\hline
\end{tabular}

rates were low, followed by high salinity and weak salinity stratification in the two lagoons. In contrast, there were large inflows to the estuary in winter and early spring. The peaks of the inflows occurred in winter (July-September), followed by a significant drop in the salinity in the estuary due to the freshwater flushing. However, differences in the salinity response to freshwater flushing can be observed between the pre-Cut year (1990, left column of Fig. 5a) and the postCut year (1998, right column of Fig. 5b). In 1990 when the estuary had limited connection without the opening of the Cut, the salinity stratification was small in the Harvey Estu- 
Left Column: year 1990 (pre-Cut)
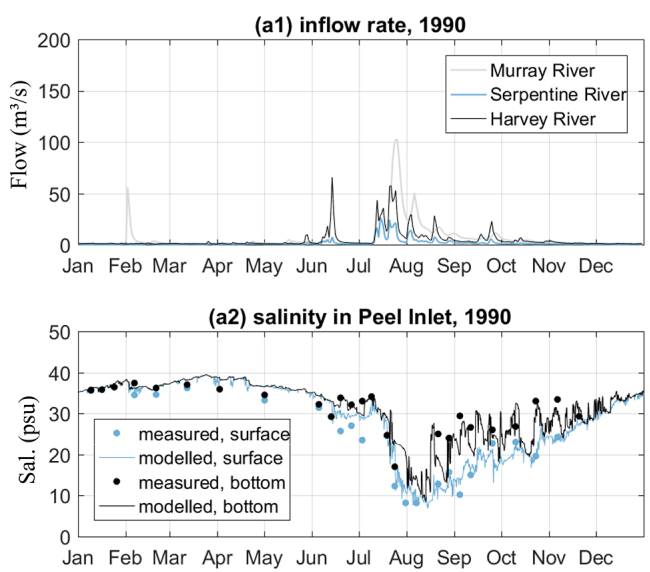

(a3) temperature in Peel Inlet, 1990
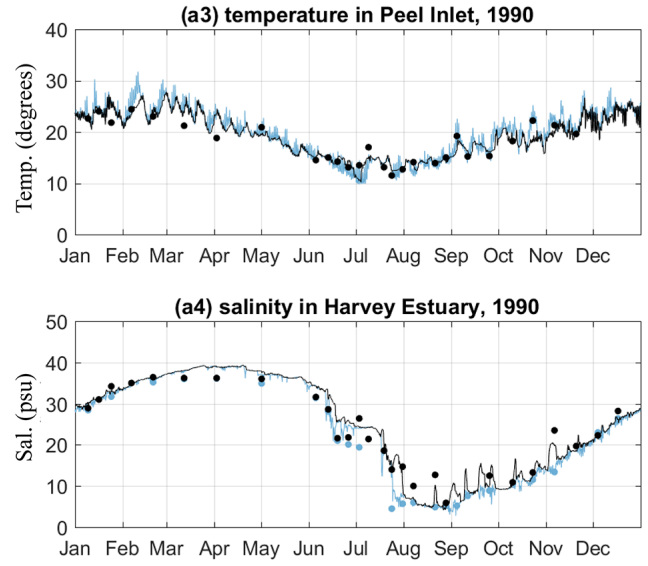

(a5) temperature in Harvey Estuary, 1990

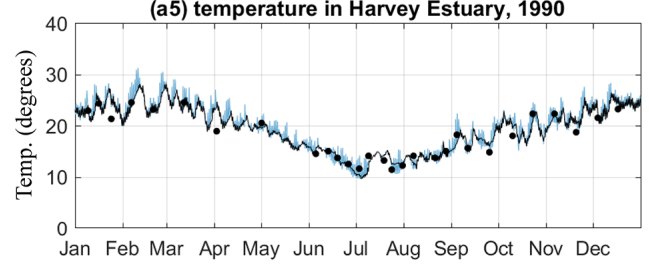

Right Column: year 1998 (post-Cut)
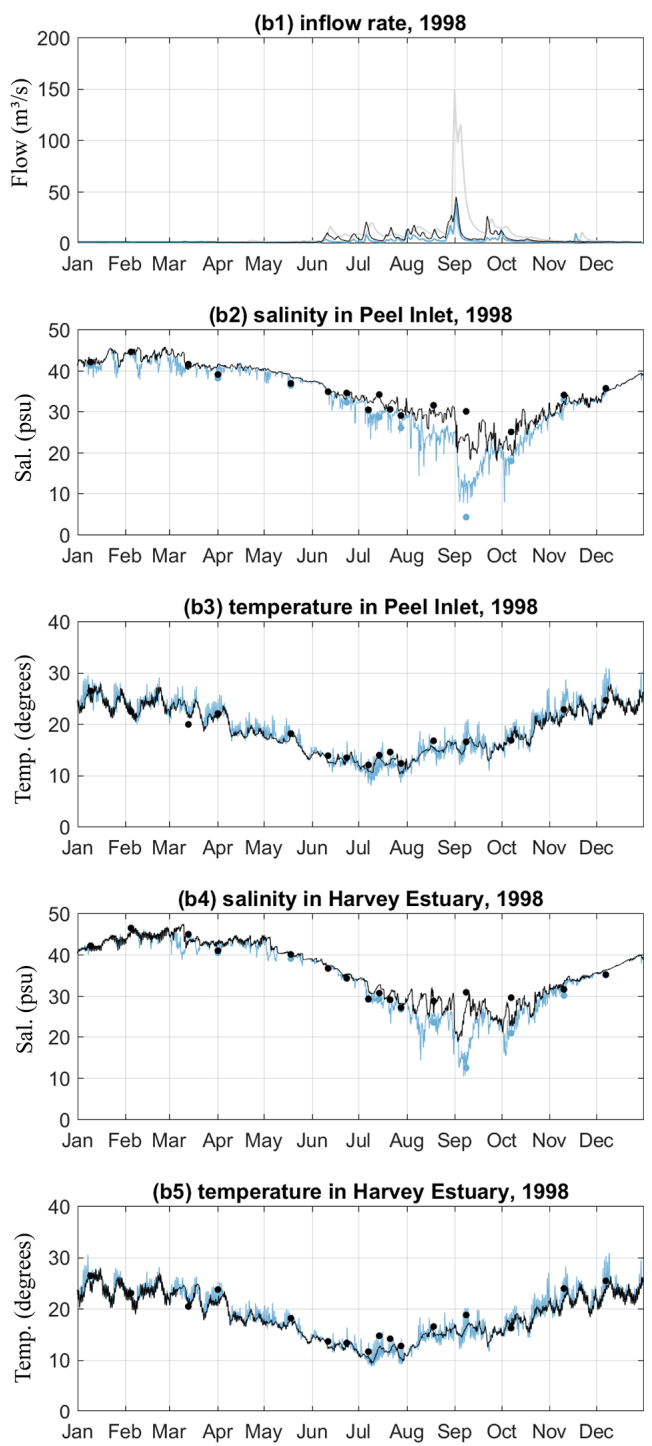

Figure 5. Annual variation in 1990 (left column, a) and 1998 (right column, b) of (1) inflow rate of the three main rivers, (2) monitored and modelled surface and bottom salinity at the centre of Peel Inlet (site PH7 in Fig. 1), (3) monitored and modelled surface and bottom water temperature at the centre of Peel Inlet, (4) monitored and modelled surface and bottom salinity at the centre of Harvey Estuary (site PH1 in Fig. 1), and (5) monitored and modelled surface and bottom water temperature at the centre of Harvey Estuary.

ary. The salinity dropped to below 5 PSU, indicating that the hydrology of Harvey Estuary was mainly dominated by the Harvey River. Whilst during 1998, with greater ocean connection due to the opening of the Cut, stronger salinity stratification was observed in the Harvey estuary, and the minimum salinity was lifted to over 10 PSU due to more seawater intrusion from the Cut. The water temperature also showed a clear seasonal signal, ranging from about $10^{\circ} \mathrm{C}$ in winter to $30^{\circ} \mathrm{C}$ in summer. The differences in the water temperature observed in the centres of the two lagoons, and between the surface and bottom waters, were small.
The opening of the Cut also affected the surface elevations of the estuary (Fig. 6). The estuary surface elevation in 1998 had a much wider range of -0.6 to $0.8 \mathrm{~m}$ compared to that in 1990 of -0.4 to $0.4 \mathrm{~m}$, indicating an enlarged tidal prism and higher magnitude of water exchange with the ocean due to the opening of the Cut.

The impacts of the changes in ocean connectivity and catchment flows on the estuary mixing is then explored with results of WRT, WFT and ME in four short theoretical scenarios (constructed to represent a matrix of open/close status of the artificial channel and wet/dry catchment inflows). 
(a) Estuary elevation in 1990

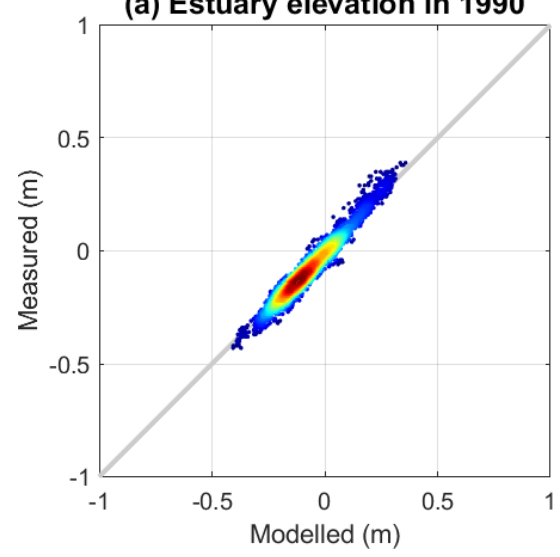

(b) Estuary elevation in 1998

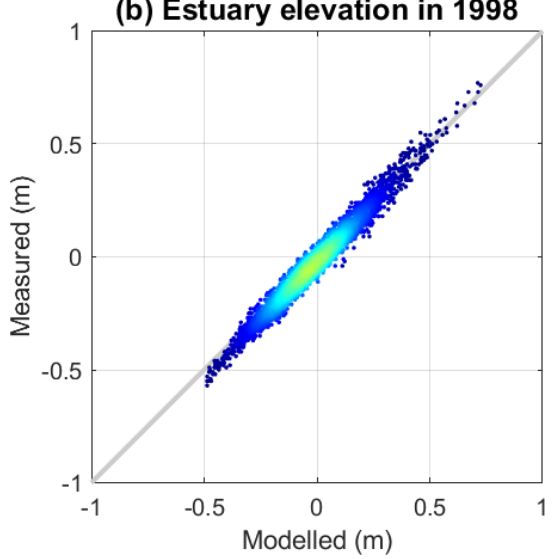

Figure 6. Modelled vs. measured surface elevation in the centre of Peel Inlet in (a) $1990(r=0.9795)$ and (b) $1998(r=0.9841)$. The grey line indicates the $1: 1$ ratio; the colour from blue to red indicates the data density from minimum to maximum.
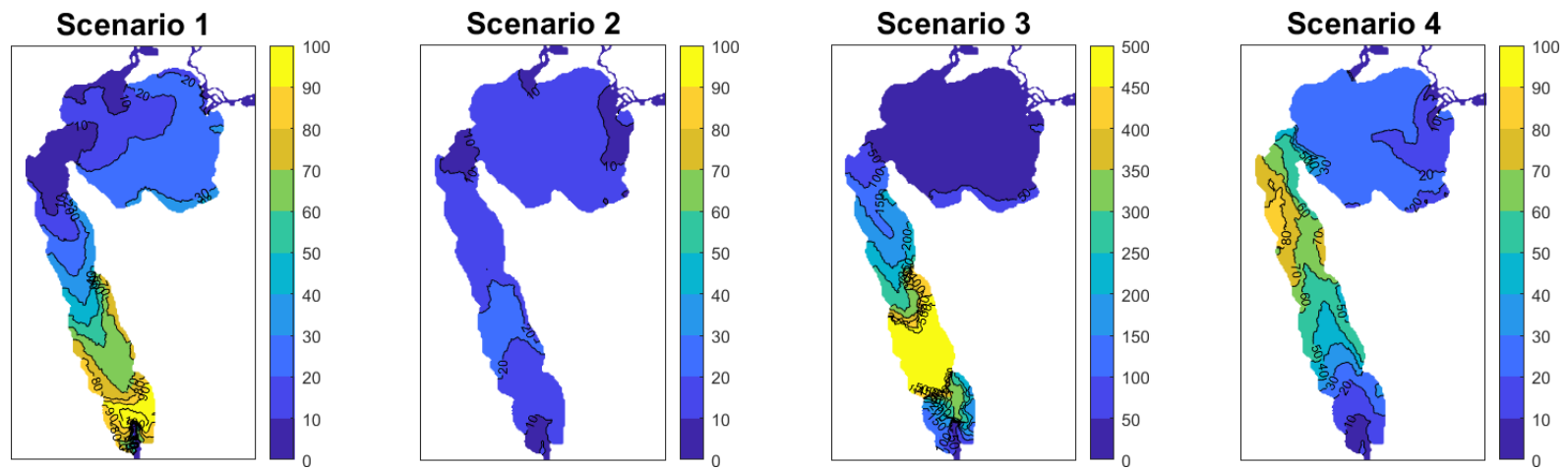

Figure 7. Spatial distribution of modelled WRT in four selected scenarios.

- Scenario 1: cut open, with inflow conditions in February 1998 (dry month with mean inflow rate of $\left.5.60 \mathrm{~m}^{3} \mathrm{~s}^{-1}\right)$

- Scenario 2: cut open, with inflow conditions in August 1998 (wet month with mean inflow rate of $\left.40.23 \mathrm{~m}^{3} \mathrm{~s}^{-1}\right)$;

- Scenario 3: cut closed, with inflow conditions in February 1998 (dry month with mean inflow rate of $\left.5.60 \mathrm{~m}^{3} \mathrm{~s}^{-1}\right)$;

- Scenario 4: cut closed, with inflow conditions in August 1998 (wet month with mean inflow rate of $\left.40.23 \mathrm{~m}^{3} \mathrm{~s}^{-1}\right)$.

The results of fluxes at the inlets, fraction of lagoon water volume exchanged daily with the sea (FVE), and average WRT, WFT, and ME are summarized in Table 5. The results highlight the hydrodynamic variability with the changes in catchment runoff and ocean connectivity. The bulk WRT ranges from $154.80 \mathrm{~d}$ with small catchment flows in the dry seasons and with only the natural channel (scenario 3) to $13.92 \mathrm{~d}$ with higher catchment flows in wet seasons and with both the natural and artificial channels (scenario 2). The exchange flux through the inlets between the lagoon and ocean increased by $\sim 3$ times due to the opening of the artificial channel. The wet months had higher ME compared to the dry months. However, it is interesting that the opening of the artificial channel, though largely reducing the water retention timescales, resulted in similar ME in the dry month and less ME in the wet month.

The spatial distributions of WRT corresponding to the changes in the inflow condition and the opening of the artificial channel are shown in Fig. 7. These maps clearly identify areas where waters are either well flushed or poorly flushed and show the Peel-Harvey system exhibiting a highly heterogeneous spatial distribution of the WRT. In all scenarios, WRT is mainly dependent on the relative distance from the inlets and on the presence of the channel. The areas connected to these channels are directly influenced by the sea and consequently their water renewal times are lower. In the wet season, the river runoff also plays a role in determining the water renewal heterogeneity. The Harvey Estuary (defined in Fig. 1) is shown to have the highest WRT than other parts of the lagoon, indicating the poor flushing in this area. 
Table 5. Model simulation results for the average water flux through the channels (Flux), fraction of lagoon volume exchanged daily with the ocean (FVE), WRT, WFT and ME in selected scenarios.

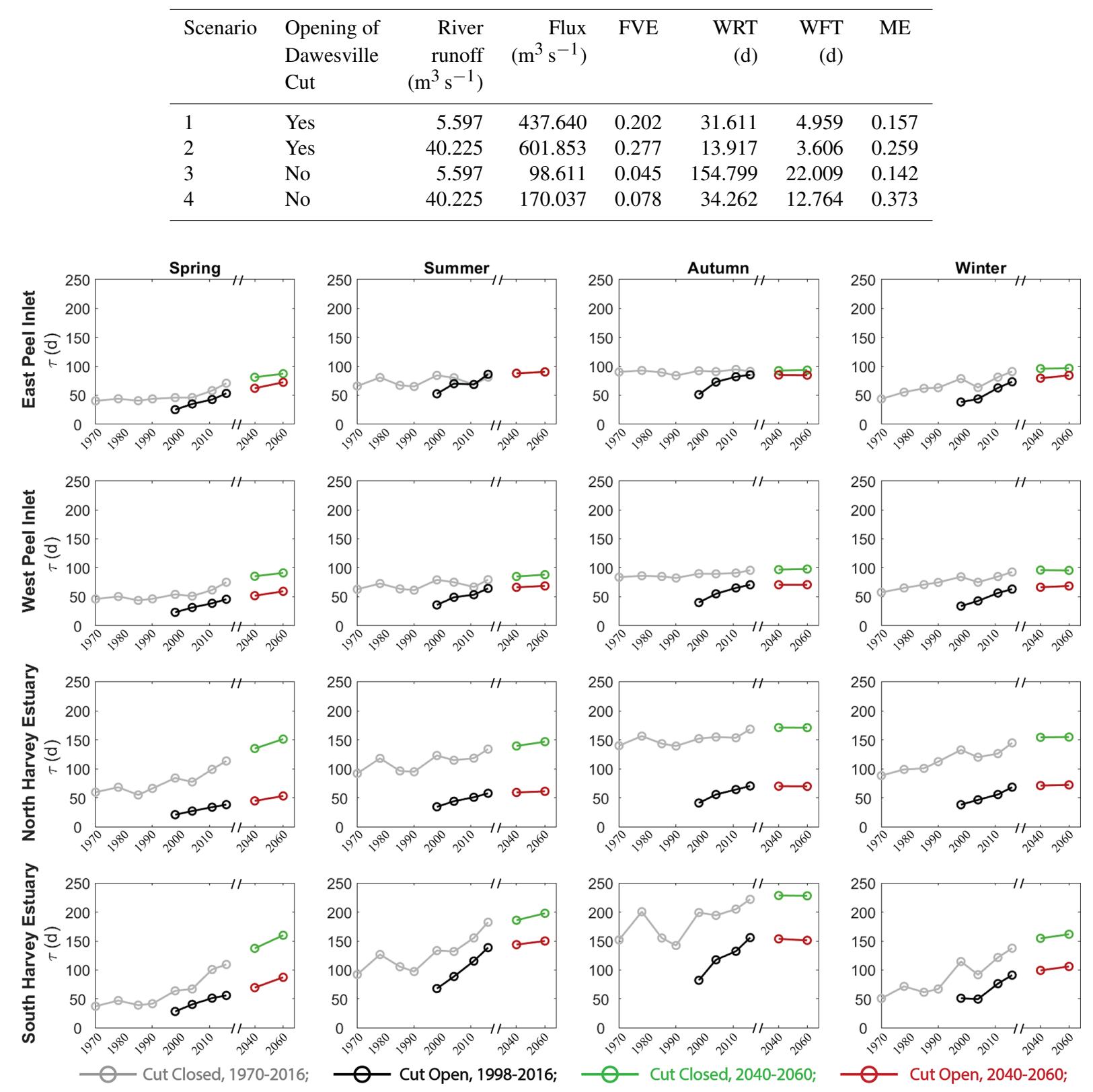

Figure 8. Mean water retention time, $\tau$, in East Peel Inlet, West Peel Inlet, North Harvey Estuary and South Harvey Estuary (see Fig. 1 extents) in simulated years and future scenarios. The data were categorized into four seasons: spring (September-November), summer (December-February), autumn (March-May) and winter (June-August).

\subsection{Long-term response of water retention to climate change and cut opening}

Water retention is highly dynamic depending on seasonal flows, tidal conditions and in different regions of the estuary. The evolution of water age, $\tau$, over time has shown a general increase from 1970 to the present, superimposed on the effect of the Cut, but with some considerable variation across the two lagoons (Fig. 8). Firstly, the wet season (winter and spring) was more sensitive to the changes in the drying climate. In the no-Cut scenarios (assuming the artificial channel was not constructed), it was predicted that $\tau$ would have increased in the Peel Inlet from about $50 \mathrm{~d}$ in 1970 to nearly double in 2016, and it increased from approximately $50 \mathrm{~d}$ in 1970 to nearly $150 \mathrm{~d}$ in 2016 in the Harvey Estuary, solely due to the drying climate trend. In contrast, the 

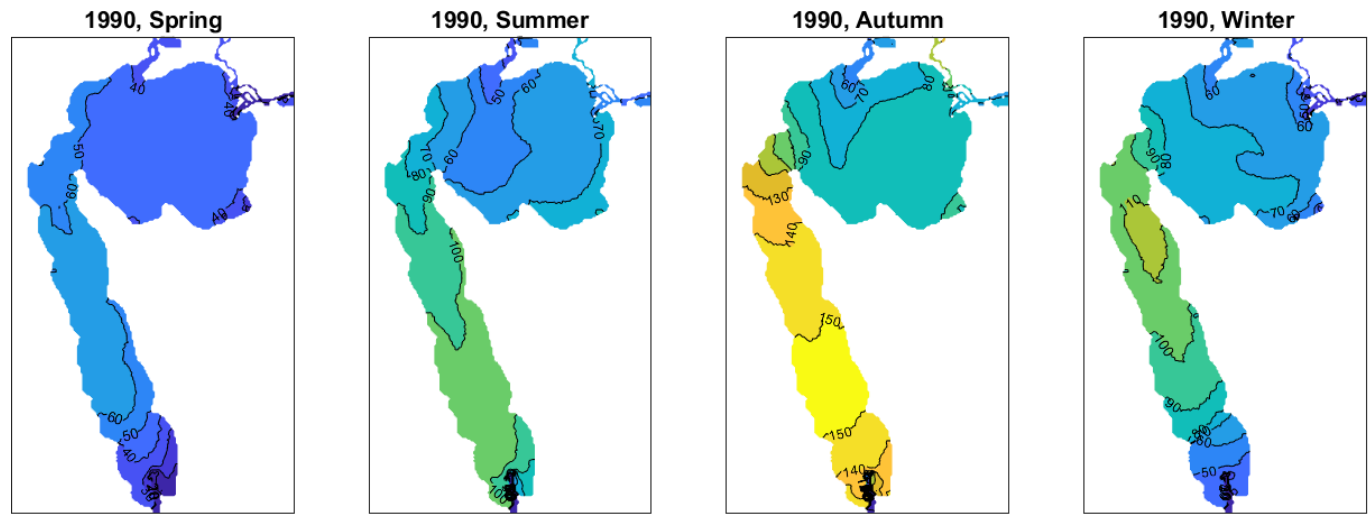

days
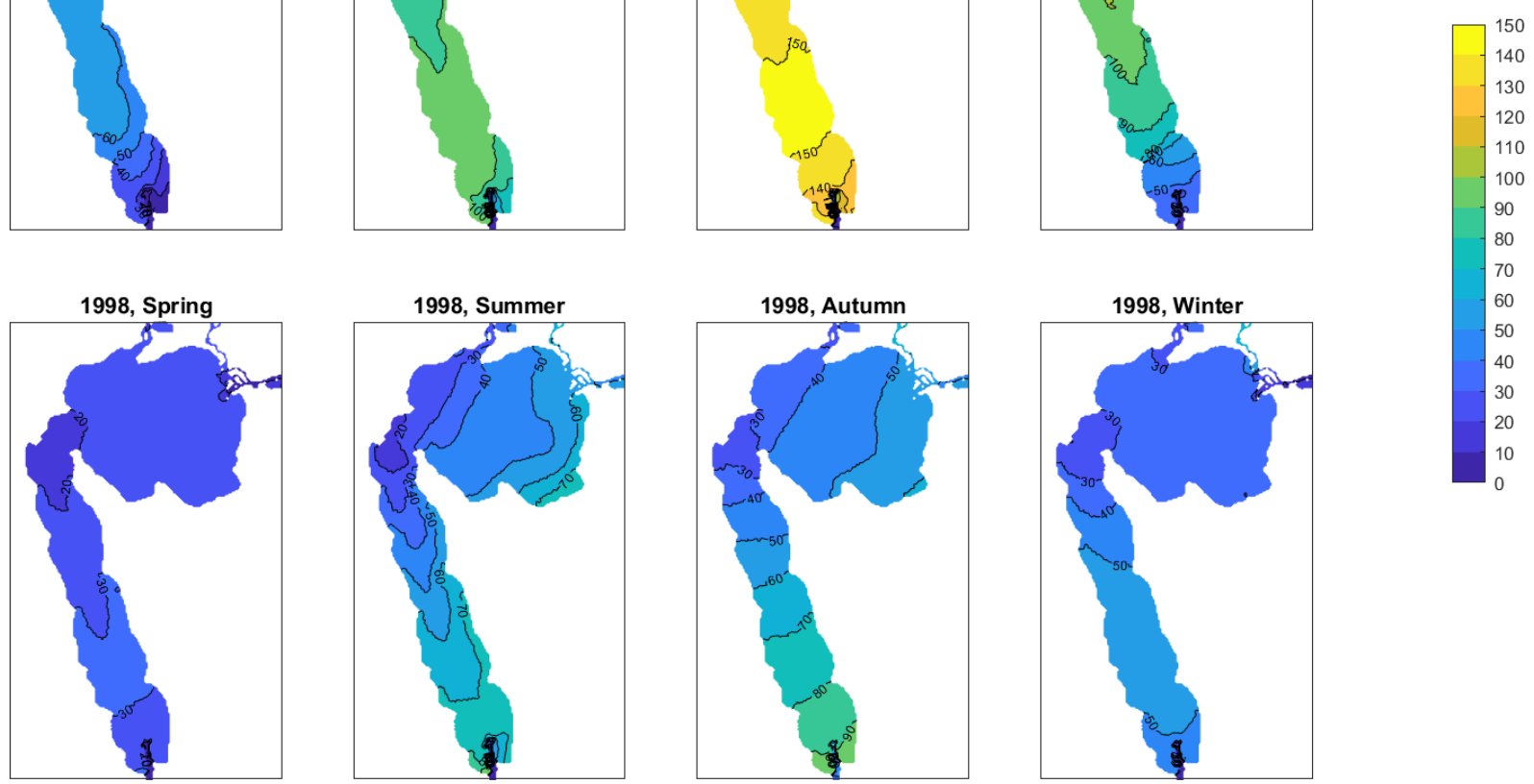

Figure 9. Spatial distribution of season-averaged water age in 1990 (top panels) and 1998 (bottom panels).

dry season (summer and autumn) conditions did not show significant changes over time in most parts of the estuary, except in the South Harvey Estuary, which is furthest from the channels. The opening of the Cut had a prominent effect by reducing $\tau$ by about $20-45 \mathrm{~d}$ in the Peel Inlet and more profoundly by $50-100 \mathrm{~d}$ in the Harvey Estuary. Yet the drying climate effect on the water age has largely cancelled out the flushing effect by the Cut in some regions. The increases in $\tau$ from 1998 to 2016, due to reduced inflows, are of the same magnitude as the level of reduction caused by the Cut opening. For example, the Cut opening reduced the $\tau$ by $28 \mathrm{~d}$ in the West Peel Inlet in 1998, yet the $\tau$ increased by $27 \mathrm{~d}$ from 1998 to 2016 due to the reduced flows. Lastly, the Harvey Estuary was most influenced by the climate changes and the Cut opening. North Harvey Estuary, directly adjacent to the Cut, was most impacted by the Cut opening, and $\tau$ was reduced by more than $110 \mathrm{~d}$. The South Harvey Estuary, which is furthest from both channels, was more sensitive to climate change, showing the greatest variation over the most recent decade. The projected climate is expected to increase the $\tau$ further in the Harvey Estuary in spring but with a relatively smaller impact at other sites and seasons.

The spatial difference in water age is further illustrated in Fig. 9, which shows a plan view of the seasonally averaged water ages in years 1990 and 1998. The spatial distribution pattern of water age is similar to the one of WRT (Fig. 7), showing that the water age in the areas adjacent to the Cut entry point has been largely reduced by the Cut opening, yet the South Harvey Estuary and some parts of the East Peel Inlet still showed high water retention.

\subsection{Long-term responses of salinity and stratification to climate change and the Cut opening}

Similar to $\tau$, the changes in salinity in response to the drying climate showed large variability in space and time, and the impact of the Cut opening acted to increase salinity in the wet season but reduced hypersalinity risks ( $>40 \mathrm{PSU}$ ) in the dry season (Fig. 10). In the no-Cut scenarios, the mean salinity during the wet season increased from < 20 PSU in 1970 to over 30 PSU in 2016. During the dry season, the changes in salinity were relatively smaller over time. The Cut opening could increase or decrease the salinity in the estuary, depending on the salinity within the estuary at the time, compared to the ocean salinity of approximately 36 PSU. If the estuary salinity was lower than the ocean salinity, the Cut opening tended to increase the salinity level and vice versa. For example, the salinity in the North Harvey Estuary increased from 17.5 to 28.3 PSU in the spring of 1998 by the Cut opening yet reduced from 51.8 to 39.8 PSU by the opening of the Cut 
in the autumn. The Cut opening has a relatively smaller influence on the salinity of Peel Inlet, which is connected with the ocean via not only the Cut but also the Mandurah Channel. The projected climate is expected to slightly increase the salinity in the Peel Inlet and Harvey Estuary, mostly in the winter and spring periods.

Hypersalinity was often observed in the summer and autumn seasons in the Peel Inlet from both the with-Cut and no-Cut scenarios. The Harvey Estuary shows an increasing salinity with the drying climate in summer and becomes hypersaline after 2011. High salinity with values over 50 PSU was observed in autumn in South Harvey Estuary in the noCut scenarios, whilst the Cut opening reduced the hypersalinity risks in autumn in the Harvey Estuary. The relationships between the hypersalinity and the catchment inflows are further investigated with monitoring data at six regular monitoring sites (Fig. 11), which highlights that the maximum salinity recorded in autumn has increased with reduced inflows, especially in the period before the Cut opening. Opening of the Cut reduced the maximum salinity at the sites near the Cut (sites PH2 and PH58) under an annual flow threshold of about $1000 \times 10^{6} \mathrm{~m}^{3} \mathrm{yr}^{-1}$. The hypersalinity risk increases with distance from the channels, especially at site PH31 in the South Harvey Estuary where salinity $>45$ PSU was often observed after the Cut opening. The maximum salinity can also be affected by other factors, such as unseasonal rainfall events in summer, which brought down the maximum salinity measured in March (Fig. 11). However, it can be concluded that the hypersalinity risks have increased in response to the catchment drying trend, and the Cut opening has reduced the sensitivity of maximum salinity to the changes in inflow rates.

The magnitude of salinity stratification (salinity difference between the bottom and surface water) in winter and spring has shown a declining trend with the drying climate, while the variations were small in summer and autumn (Fig. 12). The opening of the Cut has enhanced the rate of ocean water intrusion, which creates stronger salt stratification during the wet season when it interacts with the freshwater inflows. The salt stratification was reduced to mostly $<2$ PSU in the 2060 projection scenario, indicating weaker salt stratification due to the reduced freshwater inflows and sea level rise.

\section{Discussion}

\subsection{Changes in flushing and mixing with increasing ocean connectivity}

According to Kjerve and Magill (1989), coastal lagoons can be conveniently subdivided into choked, restricted and leaky systems based on the water exchange between the lagoon and the ocean. Umgiesser et al. (2014) compared 10 Mediterranean lagoons and classified the lagoon types based on the WRT and the fraction of lagoon water volume exchanged daily with the open sea. Based on the numbers in their comparison, the Peel-Harvey Estuary can be classified as a restricted type before the opening of the artificial channel and as a moderately leaky type after the opening of the artificial channel.

The reduction in the catchment runoff led to a smaller fraction of lagoon water volume exchanged daily with the open sea, but the magnitude is much smaller than that introduced by the opening of the artificial channel. However, the catchment runoff is shown to increase the mixing efficiency. During the dry season, the Harvey Estuary lagoon, especially the southern area, received relatively lower rates of ocean flushing that effectively lowered the ME. Higher values of ME can be found in wet seasons that enhanced the mixing of the lagoon. The increased ocean connectivity by the opening of the artificial channel, whilst enhancing exchange fluxes, is shown to lower the ME. This is similar to the findings in Umgiesser et al. (2014), where they found the exchanges with the open seas were low in the more restricted lagoon type such that the wind has more time to mix the basins well.

The impact of the artificial channel on the water transportation was further explored by the residual currents (Fig. 13), calculated as the mean currents over the period of selected scenarios described above. The results suggested that the opening of the Dawesville Cut had a strong impact on the residual currents. In the scenarios with the Cut open, strong residual currents around the Dawesville Cut are observed, and during the wet months the catchment runoff from the Serpentine River and Murray River flows to either the Mandurah channel or the Dawesville Cut. Whilst in the scenarios with the Cut closed, the surface residual currents in the Harvey Estuary were mostly moving northward, and during the wet months the catchment runoff from the Serpentine River and Murray River formed a shortcut to the Mandurah channel via the Peel Inlet; the West Peel Inlet received relatively less flushing. The results also indicated that the surface residual current speeds in the shallow water of the basins, such as the southeastern area of the Peel Inlet, were relatively lower than that in the deeper water, indicating less flushing in these areas that is coincident with the spatial distribution of WRT (Fig. 7) and water age (Fig. 9).

\subsection{Individual and combined impacts of the drying climate and artificial channel on the lagoon hydrology evolution}

The results of the long-term changes in the water age and salinity clearly showed that the hydrology in PHE was profoundly changed, corresponding to the reduced precipitation and catchment inflow as well as to the opening of the artificial channel, although other factors such as changes in air temperature, sea level rise and benthic roughness also affected the hydrology over much smaller scales. The results have highlighted magnitudes of hydrologic changes introduced by the drying climate and the complexity of the interacting impacts 

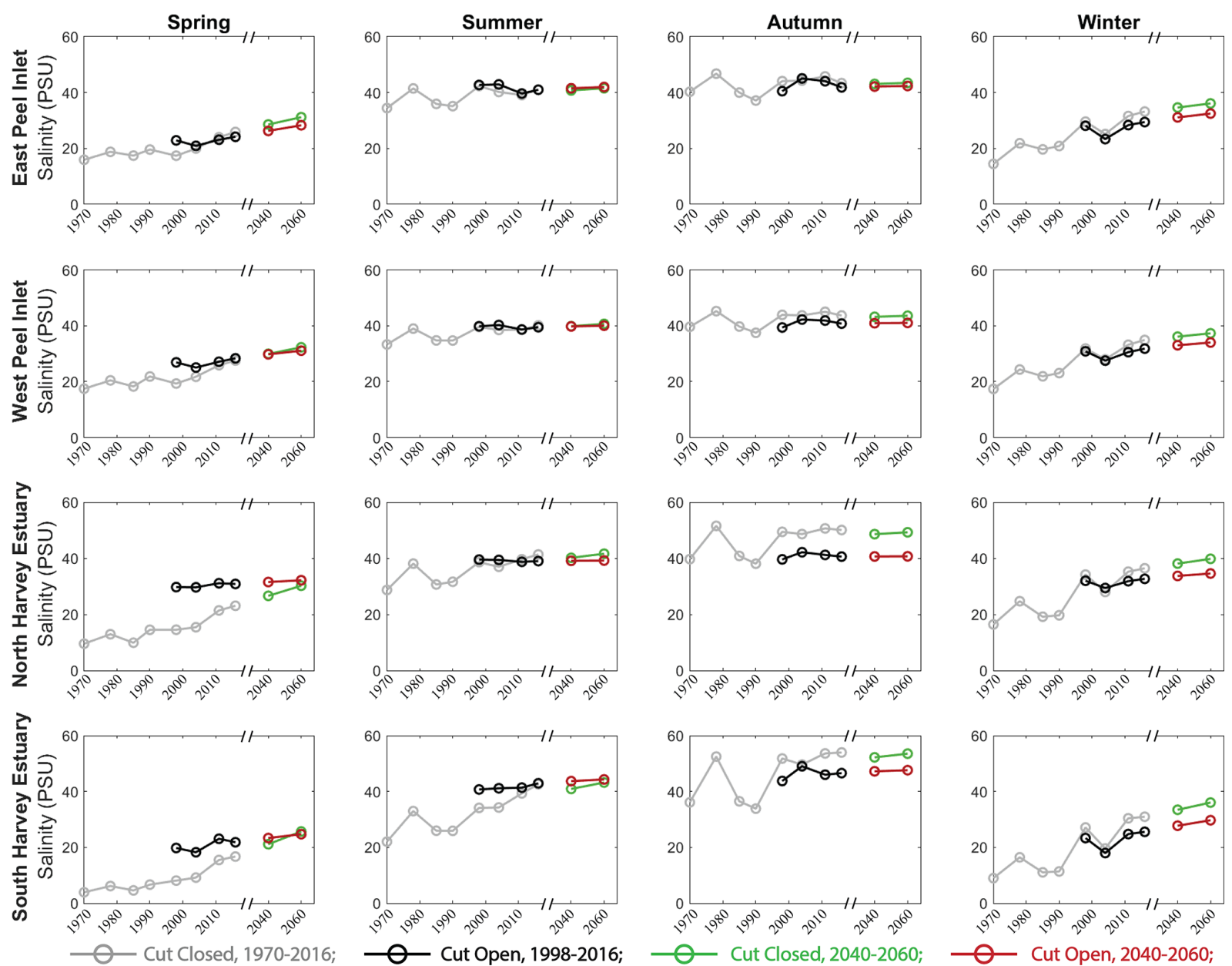

Figure 10. Changes of mean salinity in PHE in simulated years and future scenarios. As for Fig. 8, the changes are categorized into four zones and four seasons.

from climate and the artificial channel in time and space. Firstly, the artificial channel successfully improved the estuary flushing by reducing average water age by $20-110 \mathrm{~d}$; in contrast the reduced precipitation and inflow had a gradual opposite effect on the water age, and during the wet season this has almost counteracted the reduction brought about by the channel. Secondly, the drying climate caused an increase in the salinity by 10-30 PSU; whilst the artificial channel increased the salinity during the wet season, it has reduced the likelihood of hypersalinity ( $>40$ PSU) during the dry season in some areas.

The climate factor had not been considered in previous reports evaluating or predicting the consequence of the Cut opening when it was originally designed (Lord, 1998; Manda et al., 2014; Prestrelo and Monteiro-Neto, 2016), as the focus was on the flushing benefit to reduce the accumulation of nutrients and algal biomass. The findings from this study suggest that climate change has been taking effect over the period when the Cut was implemented, and from the view point of particular metrics, it is now overtaking the effect of the Cut in its significance. The lessons from this case study highlights the need to look more broadly at environmental impacts when designing or operating large-scale engineering projects on coastal lagoons, due to the potential for long-term non-stationarity in contributing river flows.

Of relevance to management, the impacts also varied spatially in this large lagoon. The water age and salinity have showed distinct responses to the climate change and Cut opening with various connections with the rivers and ocean (Figs. 8 and 10). The southern Harvey Estuary, which has the least connection with the ocean through the natural channel, is most sensitive to climate change and the opening of the artificial channel. The bulk flushing time also showed significant reduction corresponding to the Cut opening; however, it was less sensitive to the drying climate. The results of water age distribution indicated that incomplete mixing had led to area-specific retention of water. In this case, the concept of bulk flushing time therefore needs to be used with caution in such a large choked-type lagoon, because it only gives an average estimation of water retention for the whole estuary and 

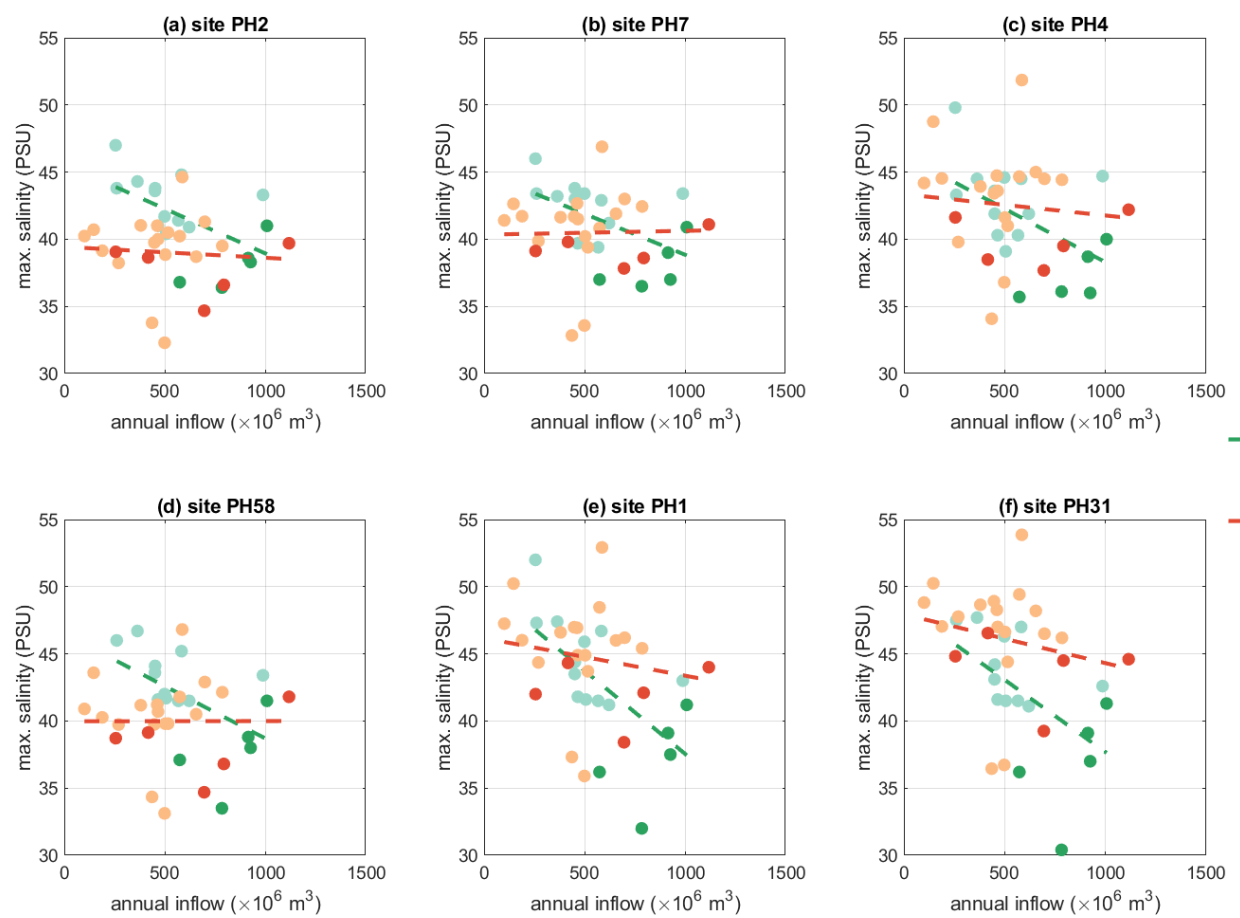

$\begin{array}{ll} & 1977-1994 \\ - & 1977-1994, \text { Summer }>15 \times 10^{6} \mathrm{~m}^{3} \\ - & \text { linear fit of } 1977-1994\end{array}$

1995-2018

- $1995-2018$, Summer $>15 \times 10^{6} \mathrm{~m}^{3}$ - - linear fit of 1995-2018

Figure 11. Maximum salinity recorded in March/April and the annual inflow in the hydrologic year (March to March) at six monitoring sites (see the site locations in Fig. 1). The darker symbols indicate the years with accidental summer rainfall events, during which the catchment inflows were higher than $15 \times 10^{6} \mathrm{~m}^{3}$.

fails to consider the strong gradients in lagoon hydrodynamics. Understanding these patterns can be important to help understand local effects on lagoon ecology (e.g. crab larval recruitment) and processes related to nutrient deposition and retention within the sediment.

Aside from changes in flushing and the mean salinity fields within the lagoon, the changes in the climate and ocean flushing also altered the hydrology in the tidal reaches of the rivers connecting to the PHE. The annual variability of salinity along the rivers (Fig. 14) indicated that there is an increasing risk of hypersalinity in the Serpentine River (connecting to the PHE from the north) and an upward movement of the salt wedge in the Murray River (the major inflow connecting PHE from the east). For example, the mean salinity at the Serpentine River mouth was about 20 PSU in 1970, then increased to $24 \mathrm{PSU}$ in 1998 and is projected to increase to over 30 PSU in 2060. In the upstream areas of the Serpentine River, the mean salinity increased from about $15 \mathrm{PSU}$ in 1970 to near 35 PSU in 2060. While there is less hypersalinity risk in the Murray River due to larger volumes of freshwater flushing, there is also a trend of increasing salinity along the river with the drying climate. The differences between the Cut-closed and Cut-open scenarios in year 1998 are much smaller than those caused by the drying climate, which indicates that the drying climate is the major cause of the salinity changes in the rivers.

\subsection{Potential impacts from the morphological change and catchment development on the Peel-Harvey hydrology}

In the current study, we assumed that the morphological change over the study period (except through the construction of the Dawesville Cut) were not significant to the overall hydrology. The morphology data we used for the model were the latest morphology dataset from the Western Australia Department of Water, obtained in 2016 (integrated DEM at $2 \mathrm{~m}$ resolution). There were no historical topography data available for each of the selected simulated years; therefore, the 2016 morphology was applied to the study period. The changes in the morphology during this long-term period could potentially affect the hydrology and the interpretation of the results.

The estuary morphology over the study period may have been modified by (1) changes to the net sedimentation of particles and (2) dredging activities related to estuary management such as marina and navigation channel developments. The net sedimentation rates in the Peel-Harvey Estuary had been investigated by a few early studies. Gabrielson and Lukatelich (1985) estimated a net sedimentation rate of about $0.4-1.5 \mathrm{~mm} \mathrm{yr}^{-1}$ in the Peel Inlet and 2.9-6.7 $\mathrm{mm} \mathrm{yr}^{-1}$ in the Harvey Estuary; Hodgkin et al. (1980) estimated an overall rate of sediment deposition of $0.3 \mathrm{~mm} \mathrm{yr}^{-1}$. Assuming the rate is constant, the maximum total sediment depo- 

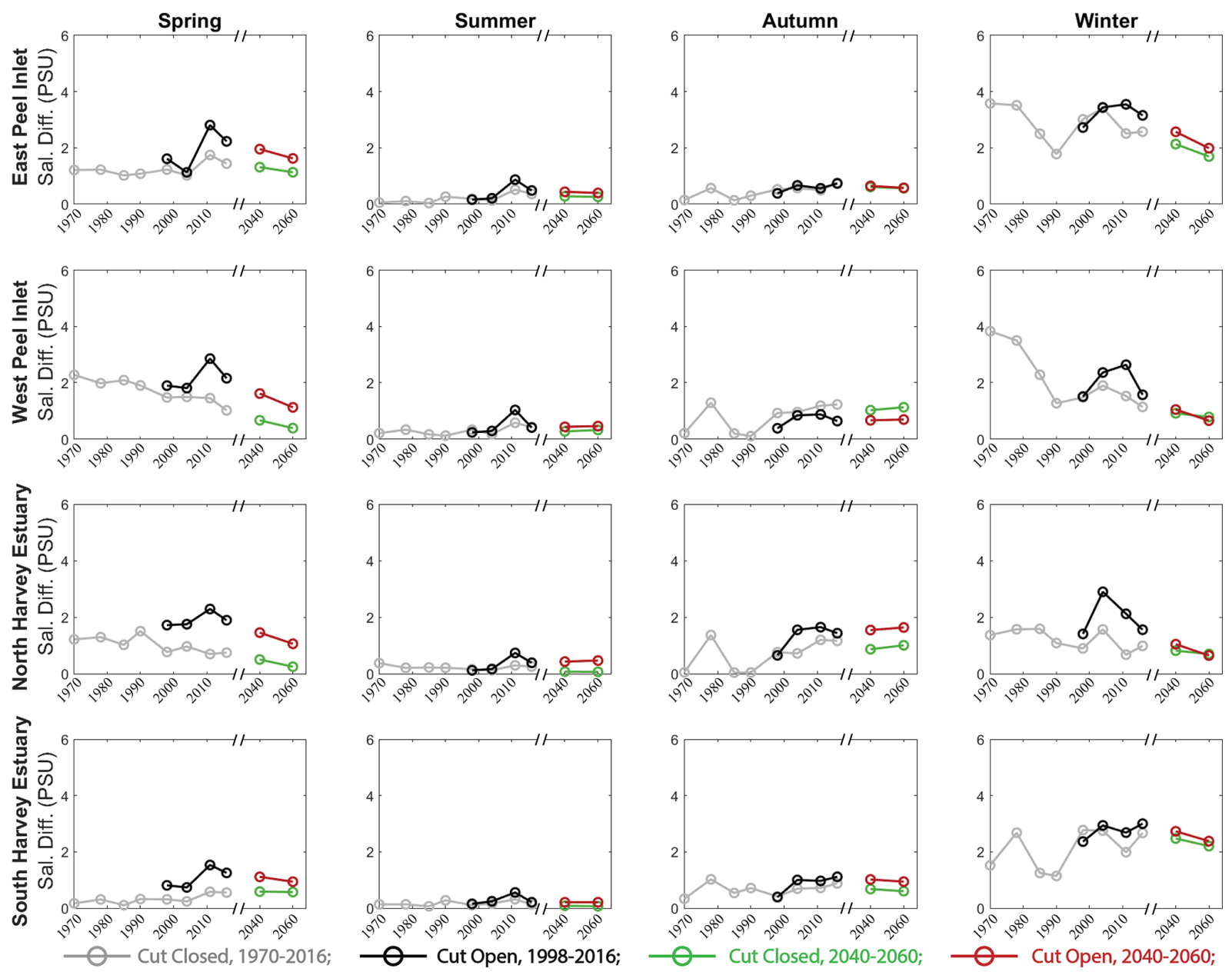

Figure 12. Changes of mean salinity difference between surface and bottom waters in PHE in the simulated years and future scenarios. As for Fig. 8, the changes are categorized into four zones and four seasons.

sition is about $75 \mathrm{~mm}$ in the Peel Inlet and $335 \mathrm{~mm}$ in the Harvey Estuary, over a period of 50 years. Note that these rates were estimated in the time before the Dawesville Cut was constructed. After the year of 1994 when the Dawesville Cut was constructed, the sediment deposition in the system, especially in the Harvey lagoon, was expected to decrease due to higher tidal flushing. The reduced flow rates over the course of the study period would also lead to a reduction in sediment loading. As we illustrated in our sensitivity tests, a change in the tidal elevation of $\pm 0.15 \mathrm{~m}$, which could be theoretically equivalent to the change in the depth of the estuary, was predicted to have caused a relatively small change to the hydrology compared to that introduced by the opening of the artificial channel and the reduced flow. Therefore, we assumed the impact of sediment deposition on the morphology was small and unlikely to change the main conclusions from the current study.

The development of canal estates and navigation channels would have further changed the local morphology, but this is expected to only slightly modify the estuary hydrology at the regional scale. For example, the Yunderup navigation channel, located at the east side of the Peel Inlet, is one of the more significant dredging projects in the Peel-Harvey Estuary in the past decades. The Yunderup channel has a length of $\sim 3 \mathrm{~km}$ (mostly in the canal estate and shallow water areas) and a width of $\sim 50 \mathrm{~m}$. The total area of this channel is $\sim 0.015 \mathrm{~km}^{2}$, which is negligible when compared to the area of the East Peel Inlet of $33.5 \mathrm{~km}^{2}$. We therefore assume that the changes brought about by the local dredging activities are negligible in analysing the estuary hydrology when looking at the average properties over the regions.

Another concern is that the catchment runoff will not only be affected by the effects of reduced rainfall, but also by landuse change, urban development and water diversion. The impacts from the catchment development on the flow conditions have been extensively discussed in the Peel-Harvey catchment modelling report (Kelsey et al., 2011), which showed different catchment developments had a combined effect on the flows. For example, land clearing is expected to increase the streamflow, while local drainage changes have led to wa- 
(a) Surface Residual Currents
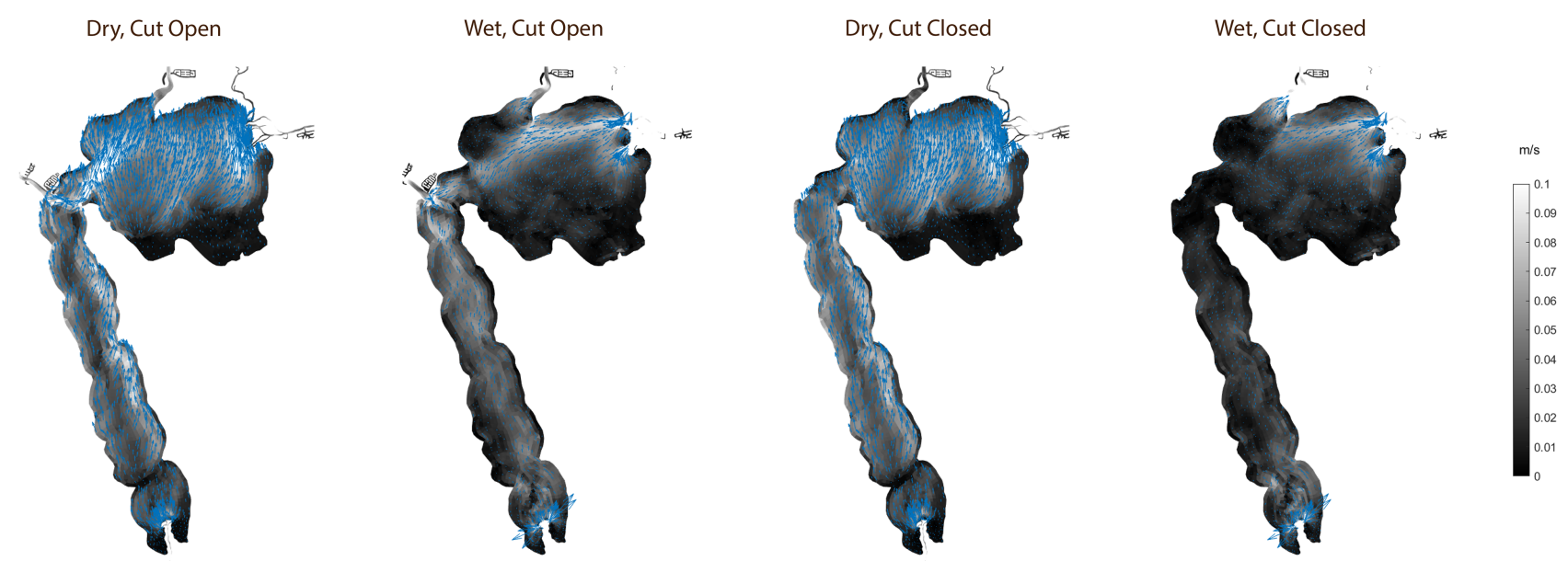

(b) Bottom Residual Currents
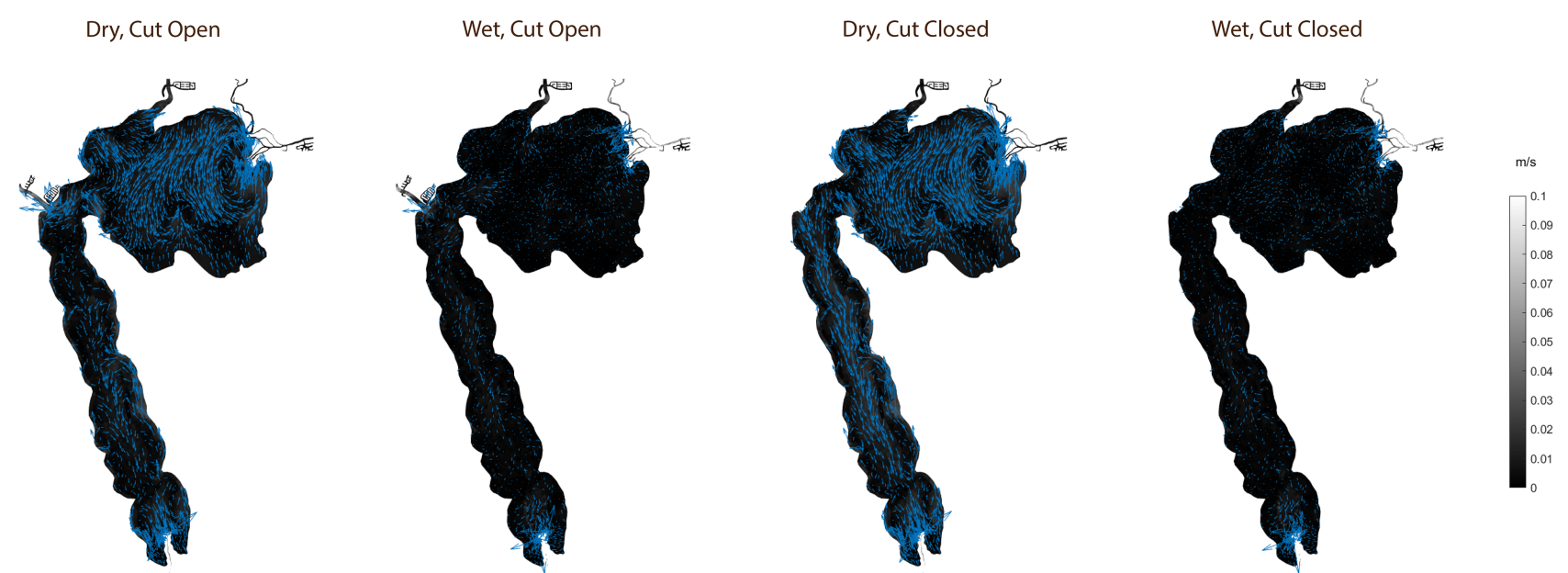

Figure 13. Plan views of residual currents in selected scenarios. The black-white colour gradient indicates the total current speed; the blue arrows indicate the current vectors.

ter diversions and reductions of the inflows. The catchment development was estimated to lead to a net increase in annual flow of about $45 \times 10^{6} \mathrm{~m}^{3}$ due to the land clearing, water supply and irrigation dams, as well as the drain activity (Kinhill Engineers, 1988; Kelsey et al., 2011). The net change in the streamflow is relatively small when compared to the reduced annual flows entering the Peel-Harvey Estuary from $1970\left(846.4 \times 10^{6} \mathrm{~m}^{3}\right)$ to $2016\left(514.4 \times 10^{6} \mathrm{~m}^{3}\right)$. Regarding the potential for changes in water diversion, there are 15 dams in the Peel-Harvey catchment and the total catchment area to be dammed is $1283 \mathrm{~km}^{2}$, which is about $12 \%$ of the total Peel-Harvey catchment $\left(10671 \mathrm{~km}^{2}\right)$ (Kelsey et al., 2011; Hennig et al., 2020). Most of the dams were completed in the time before the 1970s when our study pe- riod started. The latest catchment modelling results (Hennig et al., 2020) showed that the average annual flow in the years of 2006-2015 from unrestricted catchments was $369 \times 10^{6} \mathrm{~m}^{3} \mathrm{yr}^{-1}$, while the flow from dammed catchments was $36 \times 10^{6} \mathrm{~m}^{3} \mathrm{yr}^{-1}$, which would amount to an additional $10 \%$ increase in annual flow if these dams did not exist. It is understood that no dams in the catchment have planned environmental water releases, and it is expected that any water releases would either be a small proportion of flow. In the hydrologic models, we have used the gauged flow data combined with the catchment model outputs; therefore, the changes of the flow rates due to the catchment development have been accounted for in the model settings and our analysis. Therefore, we expect that the reduced inflow was pre- 
(a) salinity variation along the Serpentine River thalweg

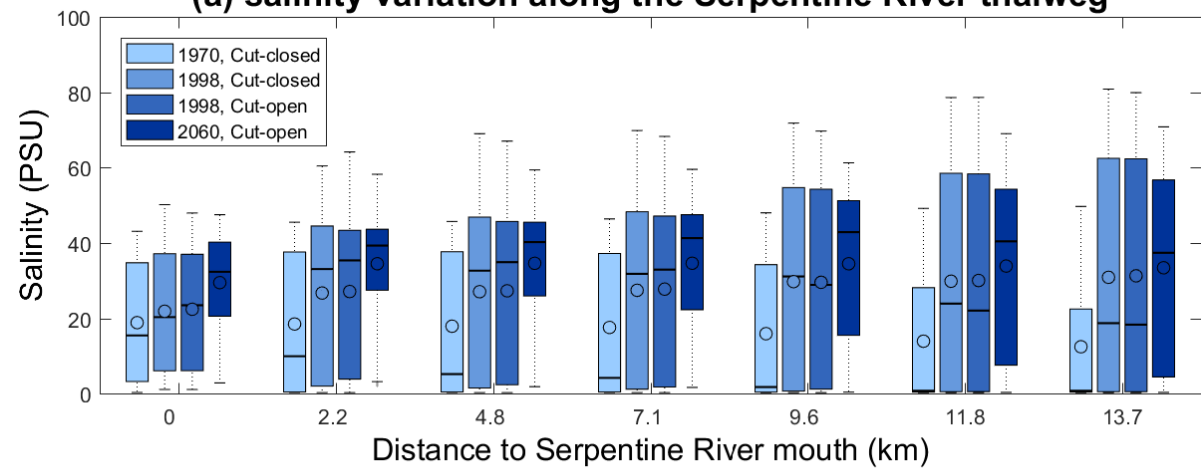

(b) salinity variation along the Murray River thalweg

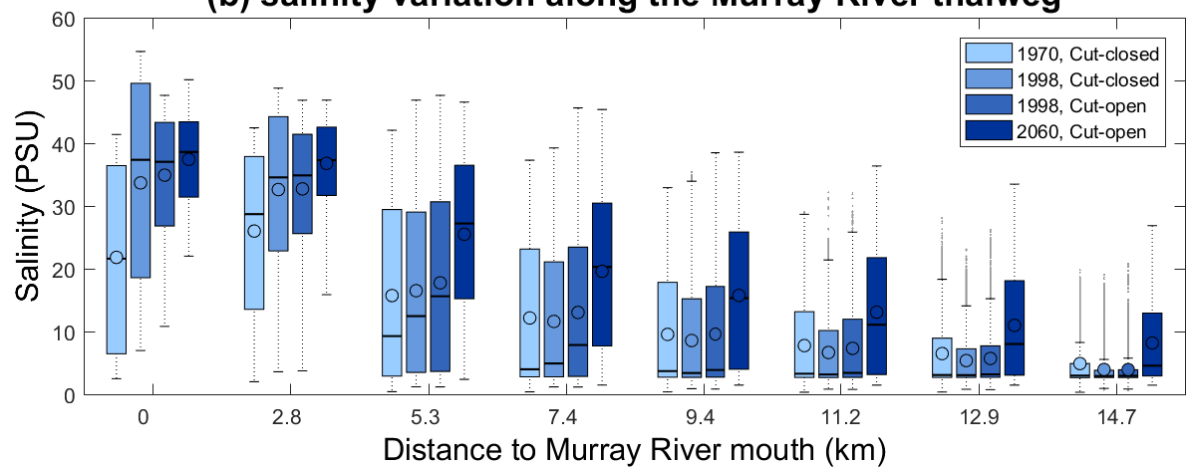

Figure 14. Longitudinal gradient in annual salinity variability in four selected scenarios (1970, 1998 without the Cut opening, 1998 with the Cut opening, and a future scenario 2060 with assumptions of reduced flow and sea level rise) moving upstream along the (a) Serpentine River and (b) Murray River.

dominantly a result of the drying climate and a key factor of reducing the nutrient loads from catchment that subsequently reduced the nutrient concentrations in the estuary.

\subsection{Uncertainty of future hydrology}

This study has investigated the hydrologic changes under projected future drying climate; however, the drying climate was idealized based on trends from a combination of climate models (Smith and Power, 2014), and the applied annual perturbations used to generate the future climate remains the subject of uncertainty. Our future climate projections for weather and flow change were based on the average trend reported from more detailed studies using an ensemble of climate models (Silberstein et al., 2012; Smith and Power, 2014). The Peel-Harvey region has experienced a widely reported decline in rainfall over the last several decades (CSIRO and BoM, 2007; IPCC, 2007; CSIRO, 2009; Hope and Ganter, 2010). The trend in rainfall decline is expected to continue, based on the climate projections from general circulation model (GCM) results (CSIRO, 2009; Smith and Power, 2014). Given that the nature of our research questions was to extrapolate the mean trend that we reported from the hindcast simulations, we focus the future scenarios on the changes of hydrology under the projected average reduction in the flow from the ensemble models (Smith and Power, 2014), with an assumed mean rate of sea level rise (Kuhn et al., 2011), to highlight the general trend and allow for prioritization of adaptation strategies such as environmental water allocation policies. This approach is somewhat simplistic in that it assumes no seasonal change in hydrologic trends, and there has been recent evidence that increasing summer floods are occurring and the winter peak flows are decreasing as a fraction of the annual total (McFarlane et al., 2020). As shown in Cloern et al. (2016), the hydrology of lagoons has been changing at a faster pace in the past decade from a combination of human activity and climate variability. The sea level of the ocean adjacent to the PHE has been rising at faster speeds in the past decades (Kuhn et al., 2011). The PHE catchment is also undergoing fast development due to the increasing population and agricultural expansion (Kelsey et al., 2011). Intensification of human activities, such as water consumption and diversion, will further affect the lagoon's hydrology and associated ecosystem, but how these factors will change in the future remains unclear. Therefore, our results related to the future prediction are simply to in- 
(a) TN

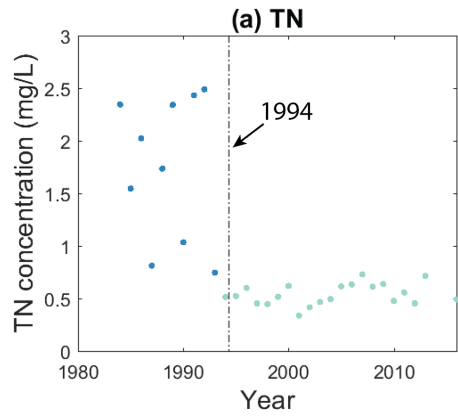

(c) TN loading vs. concentration

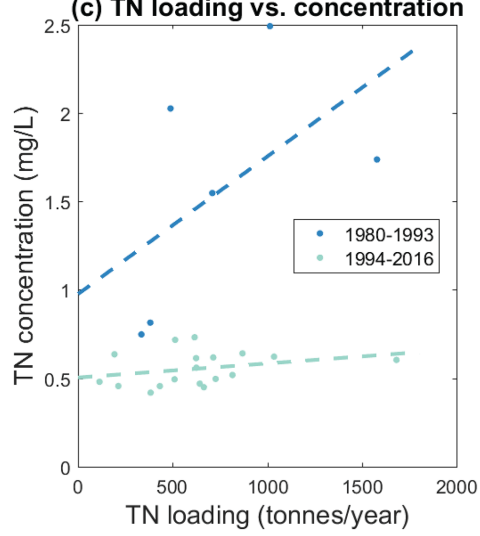

(b) TP
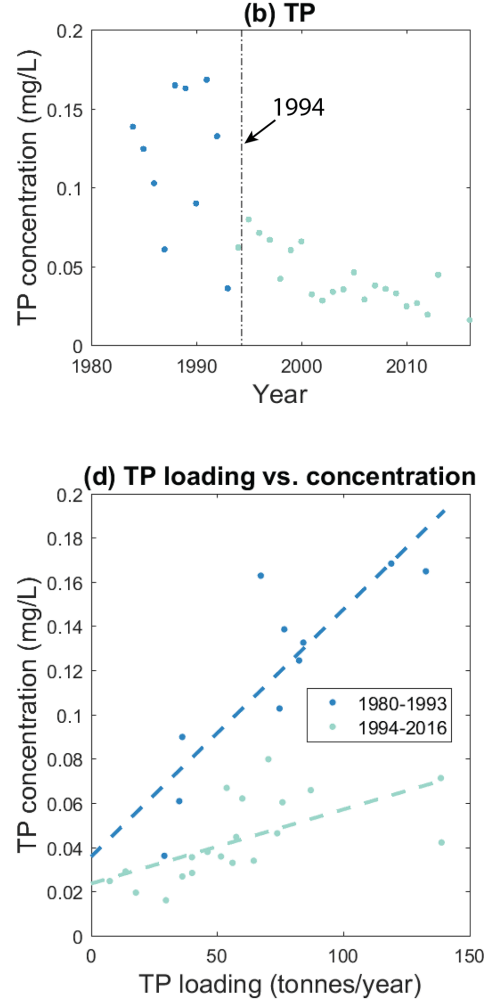

Figure 15. Changes in the mean nutrient concentration of (a) total nitrogen (TN) and (b) total phosphorus (TP) in the Peel-Harvey Estuary (based on the average of the six main monitoring stations) and their relationship with the total annual nutrient loading (c, d).

dicate the possible changes of hydrology under the projected drying climate. Continuous monitoring of the hydrology and water quality of the lagoon and its catchment must therefore be prioritized to closely observe further hydrologic change in order to provide prompt actions for management.

\subsection{Applications for estuary ecosystem management}

The Cut had an obvious and dramatic effect on increasing the export of nutrients that would have otherwise been retained (Fig. 15). Since the Cut opening in 1994, the main monitoring stations have shown that the total nitrogen (TN) concentration has been stable around $0.5 \mathrm{mg} \mathrm{L}^{-1}$ and the total phosphorus (TP) concentration has declined from 0.08 to $0.02 \mathrm{mg} \mathrm{L}^{-1}$ over time. Importantly, the increasing rate of exchange has made the estuary concentration of nutrients less sensitive to the inflow load (as demonstrated by the reduction in slope of Fig. 15c and d). The results have also revealed an increase in $\tau$ associated with the drying climate that has eroded some of the benefits associated with increased flushing following the construction of the Cut, and further reductions in flows will cause less flushing and will likely lead to a tendency for increasing nutrient accumulation over time.

The hydrologic changes led not only to changes in the nutrient concentrations but also to the mean salinity, with potential ramifications for the ecological community. In partic- ular, the phytoplankton biomass dropped dramatically since the Cut opening (Fig. 2) due to the improvement of ocean connectivity and flushing but also due to a less desirable salinity regime in summertime for the toxic cyanobacteria Nodularia spumigena that plagued the Harvey Estuary before the Cut opening. Field observations also showed that the biomass of macroalgae has decreased in the Peel Inlet, while it has increased in the Harvey Estuary since the Cut opening, which potentially reflects the reduced nutrient concentrations, increased salinity and greater light availability (Pedretti et al., 2011). The biomass of some benthic macroinvertebrates, such as the blue swimmer crabs (Portunus armatus) and the Western king prawn (Penaeus latisulcatus), also showed an increase with the Cut opening and the reduced flow in recent years (Bradby, 1997; Johnston et al., 2014). Nonetheless, several water quality concerns remain present, and problematic areas of poor quality hyper-sulfidic sediments have been identified (Kraal et al., 2013; Hallett et al., 2019), in addition to recurrent reports of harmful algal blooms and fish-kill events within the inland reaches (Valesini et al., 2019). The changes in water quality and the biological communities are anticipated to continue to evolve as the projected drying climate will further lead to areas of poor flushing and high salinity. 


\section{Conclusions and outlook}

This study has sought to analyse the hydrologic changes in the Peel-Harvey Estuary to a range of drivers, and it focused on the effects of the recent climate change trend on the hydrologic evolution in the Peel-Harvey Estuary, relative to the changes brought about by construction of the Dawesville Cut. Our results suggested that climate change in the past decades has a remarkable effect on the hydrology with the same magnitude as that caused by the opening of the artificial channel and also highlighted the complexity of their interactions. The artificial channel was effective in reducing the water retention time, especially in areas close to the channel, while the drying climate trend has acted to increase the water retention time. The artificial channel enhanced the ocean intrusion, which had a mutual effect with the drying climate to increase the estuary salinity during the wet season, but it had the opposite effect of reducing the hypersalinity during the dry season. The artificial channel increased the seawater fluxes and the salinity stratification, mostly in the Harvey Estuary, while the drying climate reduced the salinity stratification in the main body of the estuary. The changes in nutrient levels and habitat of pelagic and benthic communities related to hydrology were also discussed, which showed that the communities are sensitive to the hydrologic changes. Consideration of the projected drying trend is essential in designing management plans associated with planning for environmental water provision and setting water quality loading targets.

Data availability. The datasets generated during the current study are available from the corresponding author on request.

Supplement. The supplement related to this article is available online at: https://doi.org/10.5194/hess-24-5673-2020-supplement.

Author contributions. All the authors contributed to the design of the study. PH carried the hydrology modelling work and prepared the first draft of the article. KH provided the catchment outputs of the inflow rates and nutrient concentrations. JK and JA provided the WRF weather data. MRH was the project leader and provided technical and financial support. JK and MRH helped to interpret the model data and write the article.

Competing interests. The authors declare that they have no conflict of interest.

Acknowledgements. The authors would like to thank Fiona Valesini, Christopher Hallett and three anonymous reviewers for their valuable and constructive comments.
Financial support. This research has been supported by the Australian Research Council (grant no. LP150100451).

Review statement. This paper was edited by Hubert H. G. Savenije and reviewed by three anonymous referees.

\section{References}

Almroth-Rosell, E., Edman, M., Eilola, K., Markus Meier, H. E., and Sahlberg, J.: Modelling nutrient retention in the coastal zone of an eutrophic sea, Biogeosciences, 13, 5753-5769, https://doi.org/10.5194/bg-13-5753-2016, 2016.

Andrys, J., Lyons, T. J., and Kala, J.: Multidecadal evaluation of WRF downscaling capabilities over Western Australia in simulating rainfall and temperature extremes, J. Appl. Meteorol. Clim., 54, 370-394, https://doi.org/10.1175/JAMC-D-140212.1, 2015.

Andrys, J., Lyons, T. J., and Kala, J.: Evaluation of a WRF ensemble using GCM boundary conditions to quantify mean and extreme climate for the southwest of Western Australia (1970-1999), Int. J. Climatol., 36, 4406-4424, https://doi.org/10.1002/joc.4641, 2016.

Andrys, J., Kala, J., and Lyons, T. J.: Regional climate projections of mean and extreme climate for the southwest of Western Australia (1970-1999 compared to 2030-2059), Clim. Dynam., 48(5-6), 1723-1747, https://doi.org/10.1007/s00382-016-3169-5, 2017.

Basset, A., Elliott, M., West, R. J., and Wilson, J. G.: Estuarine and lagoon biodiversity and their natural goods and services, Estuar. Coast. Shelf Sci., 132, 1-4, https://doi.org/10.1016/j.ecss.2013.05.018, 2013.

Bates, B. C., Hope, P., Ryan, B., Smith, I., and Charles, S.: Key findings from the Indian Ocean Climate Initiative and their impact on policy development in Australia, Climatic Change, 89, 339-354, https://doi.org/10.1007/s10584-007-9390-9, 2008.

Bicknell, C.: Review of Sand Bypassing Dawesville and Mandurah, Coastal Engineering Investigation, Department for Planning and Infrastructure, Fremantle, Western Australia, 2006.

Black, R. E. and Rosher, J.: The Peel-Harvey Estuary System Study (1976-1980): Technical Report, Department of of Conservation and Environment, Perth, Western Australia, 1980.

BMT WBM: TUFLOW FV Science Manual, Brisbane, Queensland, Australia, 29 pp., 2013.

Bradby, K.: Peel-Harvey: The Decline and Rescue of an Ecosystem, Greening the Catchment Taskforce (Inc.), Western Australia, 1997.

Brearley, A. (Ed.): Ernest Hodgkin's Swanland: the estuaries and coastal lagoons of south-western Australia, University of Western Australia Press, Perth, 2005.

Bruce, L. C., Cook, P. L. M., Teakle, I., and Hipsey, M. R.: Hydrodynamic controls on oxygen dynamics in a riverine salt wedge estuary, the Yarra River estuary, Australia, Hydrol. Earth Syst. Sci., 18, 1397-1411, https://doi.org/10.5194/hess-18-1397-2014, 2014.

Chapman, P. M.: Management of coastal lagoons under climate change, Estuar. Coast. Shelf Sci., 110, 32-35, https://doi.org/10.1016/j.ecss.2012.01.010, 2012. 
Cloern, J. E., Abreu, P. C., Carstensen, J., Chauvaud, L., Elmgren, R., Grall, J., Greening, H., Johansson, J. O. R., Kahru, M., Sherwood, E. T., Xu, J., and Yin, K.: Human activities and climate variability drive fast-paced change across the world's estuarine-coastal ecosystems, Global Change Biol., 22, 513-529, https://doi.org/10.1111/gcb.13059, 2016.

Cloern, J. E., Jassby, A. D., Schraga, T. S., Nejad, E., and Martin, C.: Ecosystem variability along the estuarine salinity gradient: Examples from long-term study of San Francisco Bay, Limnol. Oceanogr., 62, S272-S291, https://doi.org/10.1002/lno.10537, 2017.

Cottingham, A., Hesp, S. A., Hall, N. G., Hipsey, M. R., and Potter, I. C.: Marked deleterious changes in the condition, growth and maturity schedules of Acanthopagrus butcheri (Sparidae) in an estuary reflect environmental degradation, Estuar. Coast. Shelf Sci., 149, 109-119, https://doi.org/10.1016/j.ecss.2014.07.021, 2014.

CSIRO: Surface water yields in south-west Western Australia: a report to the Australian Government from the CSIRO South-West Western Australia Sustainable Yields Project, Commonwealth Scientific and Industrial Research Organisation, Canberra, Australia, 2009.

CSIRO and Bureau of Meteorology: Climate change in Australia: technical report, Commonwealth Scientific and Industrial Research Organisation, Canberra, Australia, 2007.

Di Virgilio, G., Evans, J. P., Di Luca, A., Olson, R., Argüeso, D., Kala, J., Andrys, J., Hoffmann, P., Katzfey, J. J., and Rockel, B.: Evaluating reanalysis-driven CORDEX regional climate models over Australia: model performance and errors, Clim. Dynam., 53, 2985-3005, https://doi.org/10.1007/s00382-019-04672-w, 2019.

Dufour, P., Andréfouët, S., Charpy, L., and Garcia, N.: Atoll morphometry controls lagoon nutrient regime, Limnol. Oceanogr., 46, 456-461, https://doi.org/10.4319/lo.2001.46.2.0456, 2001.

Environmental Protection Authority: Water Quality Improvement Plan for the Rivers and Estuary of the Peel-Harvey System Phosphorus Management, Environmental Protection Authority, Perth, Western Australia, 2008.

Ferrarin, C., Ghezzo, M., Umgiesser, G., Tagliapietra, D., Camatti, E., Zaggia, L., and Sarretta, A.: Assessing hydrological effects of human interventions on coastal systems: Numerical applications to the Venice Lagoon, Hydrol. Earth Syst. Sci., 17, 1733-1748, https://doi.org/10.5194/hess-17-1733-2013, 2013.

Ferrarin, C., Bajo, M., Bellafiore, D., Cucco, A., De Pascalis, F., Ghezzo, M., and Umgiesser, G.: Toward homogenization of Mediterranean lagoons and their loss of hydrodiversity, Geophys. Res. Lett., 41, 5935-5941, https://doi.org/10.1002/2014GL060843, 2014.

Ferreira, J. G., Wolff, W. J., Simas, T. C., and Bricker, S. B.: Does biodiversity of estuarine phytoplankton depend on hydrology?, Ecol. Model., 187, 513-523, https://doi.org/10.1016/j.ecolmodel.2005.03.013, 2005.

Feyrer, F., Cloern, J. E., Brown, L. R., Fish, M. A., Hieb, K. A., and Baxter, R. D.: Estuarine fish communities respond to climate variability over both river and ocean basins, Global Change Biol., 21, 3608-3619, https://doi.org/10.1111/gcb.12969, 2015.

Finlayson, B. L. and McMahon, T. A.: Australia v the world: a comparative analysis of streamflow characteristics, in: Fluvial Geomorphology of Australia, edited by: Warner, R. F., Academic Press, Sydney, 17-39, 1988.
Firth, R., Kala, J., Lyons, T. J., and Andrys, J.: An analysis of regional climate simulations for Western Australia's wine regionsmodel evaluation and future climate projections, J. Appl. Meteorol. Clim., 56, 2113-2138, https://doi.org/10.1175/JAMC-D-160333.1, 2017.

Fofonoff, N. P. and Millard, R. C.: Algorithms for computation of fundamental properties of seawater, UNESCO Technical Papers in Marine Science 44, UNESCO, Paris, France, 53 pp., 1983.

Gabrielson, J. O. and Lukatelich, R. J.: Wind related resuspension of sediments in the Peel-Harvey estuarine system, Estuar. Coast. Shelf Sci., 20, 135-145, 1985.

Gamito, S.: Benthic ecology of semi-natural coastal lagoons, in the Ria Formosa (Southern Portugal), exposed to different water renewal regimes, Hydrobiologia, 555, 75-87, 2006.

Gamito, S., Gilabert, J., Diego, C. M., and Perez-Ruzafa, A.: Effects of changing environmental conditions on lagoon ecology, in: Coastal Lagoons: Ecosystem Processes and Modeling for Sustainable Use and Development, edited by: Gonenc, E. and Wolfin, J. P., CRC Press, Boca Raton, 193-229, 2005.

García-Oliva, M., Pérez-Ruzafa, Á., Umgiesser, G., McKiver, W., Ghezzo, M., De Pascalis, F., and Marcos, C.: Assessing the Hydrodynamic Response of the Mar Menor Lagoon to Dredging Inlets Interventions through Numerical Modelling, Water, 10, 959, https://doi.org/10.3390/w10070959, 2018.

Gentilli, J. (Ed.): Climates of Australia and New Zealand, Elsevier, Amsterdam, 1971.

Ghezzo, M., Guerzoni, S., Cucco, A., and Umgiesser, G.: Changes in Venice Lagoon dynamics due to construction of mobile barriers, Coast. Eng., 57, 694-708, https://doi.org/10.1016/j.coastaleng.2010.02.009, 2010.

Gillanders, B. M., Elsdon, T. S., Halliday, I. A., Jenkins, G. P., Robins, J. B., and Valesini, F. J.: Potential effects of climate change on Australian estuaries and fish utilising estuaries: A review, Mar. Freshw. Res., 62, 1115-1131, https://doi.org/10.1071/MF11047, 2011.

Gong, W., Shen, J., and Jia, J.: The impact of human activities on the flushing properties of a semi-enclosed lagoon: Xiaohai, Hainan, China, Mar. Environ. Res., 65, 62-76, https://doi.org/10.1016/j.marenvres.2007.08.001, 2008.

Hallett, C. S., Hobday, A. J., Tweedley, J. R., Thompson, P. A., McMahon, K., and Valesini, F. J.: Observed and predicted impacts of climate change on the estuaries of south-western Australia, a Mediterranean climate region, Reg. Environ. Change, 18, 1357-1373, https://doi.org/10.1007/s10113-017-1264-8, 2018.

Hallett, C. S., Valesini, F. J., Kilminster, K., Wells, N. S., and Eyre, B. D.: A rapid protocol for assessing sediment condition in eutrophic estuaries, Environ. Sci. Proc. Imp., 21, 1021-1037, 2019.

Hennig, K., Kelsey, P., Hall, J., Gunaratne, G. G., and Robb, M.: Hydrological and nutrient modelling of the Peel-Harvey estuary catchment (2006-15), Water Science Technical Series, Report, Aquatic Science Branch, Department of Water and Environmental Regulation, Perth, Western Australia, in preparation, 2020.

Hipsey, M. R., Gal, G., Arhonditsis, G. B., Carey, C. C., Elliott, J. A., Frassl, M. A., Janse, J. H., de Mora, L., and Robson, B. J.: A system of metrics for the assessment and improvement of aquatic ecosystem models, Environ. Model. Soft., 128, 104697, https://doi.org/10.1016/j.envsoft.2020.104697, 2020.

Hirsch, A. L., Evans, J. P., Di Virgilio, G., Perkins-Kirkpatrick, S. E., Argüeso, D., Pitman, A. J., Carouge, C. C., Kala, 
J., Andrys, J., Petrelli, P., and Rockel, B.: Amplification of Australian Heatwaves via Local Land-Atmosphere Coupling, J. Geophys. Res.-Atmos., 124, 13625-13647, https://doi.org/10.1029/2019JD030665, 2019.

Hodgkin, E. P., Birch, P. B., Black, R. E., and Humphries R. B.: The Peel-Harvey estuarine system study, Report no. 9, Department of Conservation and Environment, Western Australia, 1980.

Hollis, G. E.: Environmental impacts of development on wetlands in arid and semi-arid lands, Hydrolog. Sci. J., 35, 411-428, 1990.

Hope, P. and Ganter, C.: Recent and projected rainfall trends in south-west Australia and the associated shifts in weather systems, in: Managing climate change, Papers from the Greenhouse 2009 Conference, edited by: Jubb, I., Holper, P., and Cai, W., CSIRO Publishing, ISBN 978-0-643-10199-9, https://doi.org/10.1071/9780643100176, 2010.

Howarth, R. W. and Marino, R.: Nitrogen as the limiting nutrient for eutrophication in coastal marine ecosystems: Evolving views over three decades, Limnol. Oceanogr., 51, 364-376, https://doi.org/10.4319/lo.2006.51.1_part_2.0364, 2006.

Huang, P., Kilminster, K., Larsen, S., and Hipsey, M. R.: Assessing artificial oxygenation in a riverine salt-wedge estuary with a three-dimensional finite-volume model, Ecol. Eng., 118, 111125, https://doi.org/10.1016/j.ecoleng.2018.04.020, 2018.

IPCC - Intergovernmental Panel on Climate Change, in: Climate change 2007: The physical science basis, in: Contribution of Working Group I to the Fourth Assessment Report of the Intergovernmental Panel on Climate Change, edited by: Solomon, S., Qin, D., Manning, M., Chen, Z., Marquis, M., Averyt, K. B., Tignor, M., and Miller, H. L., Cambridge University Press, Cambridge, 2007.

Izrael, Y. A., Semenov, S. M., Anisimov, O. A., Anokhin, Y. A., Velichko, A. A., Revich, B. A., and Shiklomanov, I. A.: The Fourth Assessment Report of the Intergovernmental Panel on Climate Change: Working Group II contribution, Russ. Meteorol. Hydrol., 32, 551-556, 2007.

Johnston, D., Chandrapavan, A., Wise, B., and Caputi, N.: Assessment of blue swimmer crab recruitment and breeding stock levels in the Peel-Harvey Estuary and status of the Mandurah to Bunbury developing crab fishery, Fisheries Research Report No. 258, Department of Fisheries, Western Australia, 2014.

Jouon, A., Douillet, P., Ouillon, S., and Fraunie, P.: Calculations of hydrodynamic time parameters in a semi-opened coastal zone using a 3D hydrodynamic model, Cont. Shelf Res., 26, 13951415, https://doi.org/10.1016/j.csr.2005.11.014, 2006.

Kala, J., Andrys, J., Lyons, T. J., Foster, I. J., and Evans, B. J.: Sensitivity of WRF to driving data and physics options on a seasonal time-scale for the southwest of Western Australia, Clim. Dynam., 44, 633-659, https://doi.org/10.1007/s00382-014-2160-2, 2015.

Kasai, A., Kurikawa, Y., Ueno, M., Robert, D., and Yamashita, Y.: Salt-wedge intrusion of seawater and its implication for phytoplankton dynamics in the Yura Estuary, Japan, Estuar. Coast. Shelf Sci., 86, 408-414, https://doi.org/10.1016/j.ecss.2009.06.001, 2010.

Kelsey, P., Hall, J., Kretschmer, P., Quiton, B., and Shakya, D.: Hydrological and nutrient modelling of the Peel-Harvey catchment, Water Science Technical Series, Report no. 33, Department of Water, Western Australia, 2011.

Kingsford, R. T., Lemly, A. D., and Thompson, J. R.: Impacts of dams, river management and diversions on desert rivers, in: Ecol- ogy of Desert Rivers, edited by: Kingsford, R. T., Cambridge University Press, Cambridge, 203-247, 2006.

Kinhill Engineers Pty Ltd: Peel Inlet and Harvey Estuary management strategy environmental review and management programme - stage 2, Department of Agriculture and Department of Marine and Harbours, Western Australia, 1998.

Kjerfve, B. (Ed.): Coastal lagoons, in: Coastal Lagoon Processes, Elsevier Oceanographic Series, Elsevier Science, Amsterdam, 18, 1994.

Kjerfve, B. and Magill, K. E.: Geographic and hydrodynamic characteristics of shallow coastal lagoons, Mar. Geol., 88, 187-199, 1989.

Kjerfve, B., Schettini, C. A. F., Knoppers, B., Lessa, G., and Ferreira, H. O.: Hydrology and salt balance in a large, hypersaline coastal lagoon: Lagoa de Araruama, Brazil, Estuar. Coast. Shelf Sci., 42, 701-725, https://doi.org/10.1006/ecss.1996.0045, 1996.

Knoppers, B., Kjerfve, B., and Carmouze, J. P.: Trophic state and water turn-over time in six choked coastal lagoons in Brazil, Biogeochemistry, 14, 149-166, https://doi.org/10.1007/BF00002903, 1991.

Koutitonsky, V. G.: Three-dimensional structure of wind-driven currents in coastal lagoons, in: Coastal Lagoons: Ecosystem Processes and Modeling for Sustainable Use and Development, edited by: Gonenc, E. and Wolfin, J. P., CRC Press, Boca Raton, 376-391, 2005.

Kraal, P., Burton, E. D., and Bush, R. T.: Iron monosulfide accumulation and pyrite formation in eutrophic estuarine sediments, Geochim. Cosmochim. Ac., 122, 75-88, 2013.

Kuhn, M., Tuladhar, D., and Corner, R.: Visualising the spatial extent of predicted coastal zone inundation due to sea level rise in south-west Western Australia, Ocean Coast. Manage., 54, 796806, https://doi.org/10.1016/j.ocecoaman.2011.08.005, 2011.

Legović, T., Zutić, V., Gretić, Z., Cauwet, G., Precali, R., and Viličié, D.: Eutrophication in the Krka estuary, Mar. Chem., 46, 203-215, https://doi.org/10.1016/0304-4203(94)90056-6, 1994.

Li, Y., Feng, H., Zhang, H., Sun, J., Yuan, D., Guo, L., Nie, J., and Du, J.: Hydrodynamics and water circulation in the New York/New Jersey Harbor: A study from the perspective of water age, J. Mar. Syst., 199, 103219, https://doi.org/10.1016/j.jmarsys.2019.103219, 2019.

Lord, D. A.: Dawesville Channel Monitoring Programme technical review, Water and Rivers Commission Report WRT 28, Water and Rivers Commission, Western Australia, 1998.

Manda, A. K., Giuliano, A. S., and Allen, T. R.: Influence of artificial channels on the source and extent of saline water intrusion in the wind tide dominated wetlands of the southern Albemarle estuarine system (USA), Environ. Earth Sci., 71, 44094419, https://doi.org/10.1007/s12665-013-2834-9, 2014.

McFarlane, D., George, R., Ruprecht, J., Charles, S., and Hodgson, G.: Runoff and groundwater responses to climate change in South West Australia, J. Roy. Soci. West. Aust., 103, 9-27, 2020.

Monsen, N. E., Cloern, J. E., Lucas, L. V., and Monismith, S. G.: A comment on the use of flushing time, residence time, and age as transport time scales, Limnol. Oceanogr., 47, 1545-1553, https://doi.org/10.4319/lo.2002.47.5.1545, 2002.

Muleta, M. K. and Nicklow, J. W.: Sensitivity and uncertainty analysis coupled with automatic calibration for a distributed watershed model, J. Hydrol., 306, 127-145, 2004. 
Newton, A., Icely, J., Cristina, S., Brito, A., Cardoso, A. C., Colijn, F., Riva, S. D., Gertz, F., Hansen, J. W., Holmer, M., Ivanova, K., Leppäkoski, E., Canu, D. M., Mocenni, C., Mudge, S., Murray, N., Pejrup, M., Razinkovas, A., Reizopoulou, S., Pérez-Ruzafa, A., Schernewski, G., Schuber, H., Carr, L. C., Solidoro, C., Viaroli, P., and Zaldívar, J. M.: An overview of ecological status, vulnerability and future perspectives of European large shallow, semi-enclosed coastal systems, lagoons and transitional waters, Estuar. Coast. Shelf Sci., 140, 95-122, https://doi.org/10.1016/j.ecss.2013.05.023, 2014.

Newton, A., Brito, A. C., Icely, J. D., Derolez, V., Clara, I., Angus, S., Schernewski, G., Inácio, M., Lillebø, A. I., Sousa, A. I., Béjaoui, B., Solidoro, C., Tosic, M., Cañedo-Argüelles, M., Yamamuro, M., Reizopoulou, S., Tseng, H. C., Canu, D., Roselli, L. Maanan, M., Cristina, S., Ruiz-Fernández, A. C., Lima, R. F., Kjerfve, B., Rubio-Cisneros, N., Pérez-Ruzafa, A., Marcos, C., Pastres, R., Pranovi, F., Snoussi, M., Turpie, J., Tuchkovenko, Y., Dyack, B., Brookes, J., Povilanskas, R., and Khokhlov, V.: Assessing, quantifying and valuing the ecosystem services of coastal lagoons, J. Nat. Conserv., 44, 50-65, https://doi.org/10.1016/j.jnc.2018.02.009, 2018.

Nicholls, R. J. and Hoozemans, F. M. J.: The Mediterranean: vulnerability to coastal implications of' climate change, Ocean Coast. Manage., 31, 105-132, 1996.

Nicholls, R. J., Hoozemans, F. M. J., and Marchand, M.: Increasing flood risk and wetland losses due to global sealevel rise: regional and global analyses, Global Environ. Change, 9, S69-S87, 1999.

Odebrecht, C., Abreu, P. C., and Carstensen, J.: Retention time generates short-term phytoplankton blooms in a shallow microtidal subtropical estuary, Estuar. Coast. Shelf Sci., 162, 35-44, https://doi.org/10.1016/j.ecss.2015.03.004, 2015.

Paerl, H. W., Valdes, L. M., Peierls, B. L., Adolf, J. E., and Harding, L. W.: Anthropogenic and climatic influences on the eutrophication of large estuarine ecosystems, Limnol. Oceanogr., 51, 448462, https://doi.org/10.4319/lo.2006.51.1_part_2.0448, 2006.

Paerl, H. W., Hall, N. S., Peierls, B. L., Rossignol, K. L., and Joyner, A. R.: Hydrologic Variability and Its Control of Phytoplankton Community Structure and Function in Two Shallow, Coastal, Lagoonal Ecosystems: The Neuse and New River Estuaries, North Carolina, USA, Estuar. Coast., 37, 31-45, https://doi.org/10.1007/s12237-013-9686-0, 2014.

Pedretti, Y. M., Kobryn, H. T., Sommerville, E. F., and Wienczugow, K.: Snapshot Survey of the Distribution and Abundance of Seagrass and Macroalgae in the Peel-Harvey Estuary from November/December 2009, Unpublished Technical Report, Marine and Freshwater Laboratories, Murdoch University, Murdoch, 2011.

Pérez-Ruzafa, A., Marcos, C., and Pérez-Ruzafa, I. M.: Mediterranean coastal lagoons in an ecosystem and aquatic resources management context, Phys. Chem. Earth, 36, 160-166, https://doi.org/10.1016/j.pce.2010.04.013, 2011.

Petersen, J. K., Hansen Würgler, J., Laursen Brogaard, M., Clausen, P., Carstensen, J., and Conley, D. J.: Regime shift in a coastal marine ecosystem, Ecol. Appl., 18, 497-510, https://doi.org/10.1890/07-0752.1, 2008.

Potter, I. C., Chuwen, B. M., Hoeksema, S. D., and Elliott, M.: The concept of an estuary: A definition that incorporates systems which can become closed to the ocean and hypersaline, Estuar. Coast. Shelf Sci., 87, 497-500, https://doi.org/10.1016/j.ecss.2010.01.021, 2010.
Prestrelo, L. and Monteiro-Neto, C.: Before-after environmental impact assessment of an artificial channel opening on a southwestern Atlantic choked lagoon system, J. Fish Biol., 89, 735752, https://doi.org/10.1111/jfb.13012, 2016.

Rogers, P., Hall, N., and Valesini, F.: Science strategy for the PeelHarvey Estuary, prepared for the Peel-Harvey Catchment Council, Centre for Fish and Fisheries Research, Murdoch University, Murdoch, 2010.

Sahu, B. K., Pati, P., and Panigrahy, R. C.: Environmental conditions of Chilika Lake during pre and post hydrological intervention: An overview, J. Coast. Conserv., 18, 285-297, https://doi.org/10.1007/s11852-014-0318-z, 2014.

Scavia, D., Field, J. C., Boesch, D. F., Buddemeier, R. W., Burkett, V., Cayan, D. R., Fogarty, M., Harwell, M. A., Howarth, R. W., Mason, C., Reed, D. J., Royer, T. C., Sallenger, A. H., and Titus, J. G..: Climate change impacts on U.S. coastal and marine ecosystems, Estuaries, 25, 149-164, 2002.

Sheldon, J. E. and Alber, M.: The calculation of estuarine turnover times using freshwater fraction and tidal prism models: a critical evaluation, Estuar. Coast., 29, 133-146, 2006.

Silberstein, R. P., Aryal, S. K., Durrant, J., Pearcey, M., Braccia, M., Charles, S. P., Boniecka, L., Hodgson, G. A., Bari, M. A., Viney, N. R., and McFarlane, D. J.: Climate change and runoff in south-western Australia, J. Hydrol., 475, 441-455, https://doi.org/10.1016/j.jhydrol.2012.02.009, 2012.

Smith, I. and Power, S.: Past and future changes to inflows into Perth (Western Australia) dams, J. Hydrol. Reg. Stud., 2, 84-96, https://doi.org/10.1016/j.ejrh.2014.08.005, 2014.

Smith, N.: Water, salt and heat balances of coastal lagoons, in: Coastal Lagoon Processes, Elsevier Oceanographic Series 60, edited by: Kjerfve, B., Elsevier, New York, 69-102, 1994.

Spaulding, M.: Modeling of circulation and dispersion in coastal lagoons, in: Coastal Lagoon Processes, Elsevier Oceanographic Series 60, edited by: Kjerfve, B., Elsevier, New York, 103-132, 1994.

Umgiesser, G., Ferrarin, C., Cucco, A., De Pascalis, F., Bellafiore, D., Ghezzo, M., and Bajo, M.: Comparative hydrodynamics of 10 Mediterranean lagoons by means of numerical modeling, J. Geophys. Res.-Oceans, 119, 2212-2226, https://doi.org/10.1002/2013JC009512, 2014.

Valesini, F. J., Hallett, C. S., Hipsey, M. R., Kilminster, K. L., Huang, P., and Hennig, K.: Peel-Harvey Estuary, Western Australia, in: Coasts and Estuaries: the future, edited by: Wolanski, E., Day, J. W., Elliott, M., and Ramachandran, R., Elsevier, Amsterdam, the Netherlands, 103-120, 2019.

Watanabe, K., Kasai, A., Antonio, E. S., Suzuki, K., Ueno, M., and Yamashita, Y.: Influence of salt-wedge intrusion on ecological processes at lower trophic levels in the Yura Estuary, Japan, Estuar. Coast. Shelf Sci., 139, 67-77, https://doi.org/10.1016/j.ecss.2013.12.018, 2014.

Welsh, W. D., Vaze, J., Dutta, D., Rassam, D., Rahman, J. M., Jolly, I. D., Wallbrink, P., Podger, G. M., Bethune, M., Hardy, M. J., Teng, J., and Lerat, J.: An integrated modelling framework for regulated river systems, Environ. Model. Softw., 39, 81-102, https://doi.org/10.1016/j.envsoft.2012.02.022, 2013.

Williamson, S. C., Rheuban, J. E., Costa, J. E., Glover, D. M., and Doney, S. C.: Assessing the Impact of Local and Regional Influences on Nitrogen Loads to Buzzards Bay, MA, Front. Mar. Sci., 3, 279, https://doi.org/10.3389/fmars.2016.00279, 2017. 
Wu, J.: Wind-stress coefficients over sea surface from breeze to hurricane, J. Geophys. Res., 87, 9704-9706, 1982.

Zaldívar, J., Cardoso, A. C., Viaroli, P., De Wit, R., Ibañez, C., Reizopoulou, S., Razinkovas, A., Basset, A., Holmer, M., and Murray, N.: Eutrophication in transitional waters: an overview, Transit. Waters Monogr., 2, 1-78, https://doi.org/10.1285/i18252273v2n1p1, 2008.
Zhu, Y., McCowan, A., and Cook, P. L. M.: Effects of changes in nutrient loading and composition on hypoxia dynamics and internal nutrient cycling of a stratified coastal lagoon, Biogeosciences, 14, 4423-4433, https://doi.org/10.5194/bg-14-4423-2017, 2017. 